\begin{tabular}{ll}
\multicolumn{1}{c}{ Abstract } \\
Title of Document: & FACTORS RELATED TO EARLY \\
& TERMINATION FROM WORK FOR YOUTH \\
& WITH DISABILITIES \\
& \\
& Roxanna Nasseri Pebdani, Doctor of Philosophy, \\
& 2012 \\
Directed By: & $\begin{array}{l}\text { Dr. Courtland C. Lee, Department of } \\
\text { Counseling, Higher Education, and Special } \\
\text { Education }\end{array}$
\end{tabular}

Youth with disabilities face significant barriers in achieving positive post-high school outcomes, particularly when transitioning out of high school and entering the workforce, a problem that has been documented and studied by many researchers. The impact of previous work experience has long been viewed as related to positive outcomes when youth with disabilities transition from high school to work. However, very few studies have looked at specific factors leading to poor post-school outcomes for youth with disabilities like early termination of work. This study utilizes a national database of youth in a transition program to determine what factors influenced early termination of a job placement. Hierarchical Linear Modeling is used to explore how early termination is impacted by race, gender, socioeconomic status, previous vocational education, previous work experience, type of job, and whether or not the youth is receiving Supplemental Security Income (SSI) or utilizing the Ticket to Work (TTW). Results from this study can help to identify which youth may be particularly at-risk to terminate early from a job placement program, giving service providers the opportunity to implement interventions that help at-risk students succeed. 


\title{
FACTORS RELATED TO EARLY TERMINATION FROM WORK FOR YOUTH WITH DISABILITIES
}

\author{
By \\ Roxanna Nasseri Pebdani \\ Dissertation submitted to the Faculty of the Graduate School of the \\ University of Maryland, College Park, in partial fulfillment \\ of the requirements for the degree of \\ Doctor of Philosophy \\ 2012
}

Advisory Committee:

Professor Courtland C. Lee, Chair

Professor Ellen Fabian

Professor Mary Ann Hoffman

Professor Matt Miller

Professor Linda Valli 
(C) Copyright by

Roxanna Nasseri Pebdani

2012 
Acknowledgements

I would like to thank my grandmother, Mommy Soori, for calling me "Doctor" since approximately the day I was born and for always having faith in me. To my Mom and Dad, you instilled a work ethic in me that made this possible and ensured that I had the necessary supports throughout my life to make me the best student I could be. To my cousin, Ibie, thank you for listening to me when I was about to lose it and pulling my hair out, and for editing papers, emails, and everything else throughout my graduate career. To Erik, I could not have done this without your support, constantly listening to me when I was freaking out, standing by me when it felt like everything was falling apart, and always having faith in me. To the rest of my family (Maman Bozorgeh, Baba Bozorgeh, Baba Jan, Khaleh Azi, Khaleh Mehrdokht, Ameh Mahrokh, Ameh Pari, Amoo Shahrokh, and Amoo Kia and beyond), thank you for always encouraging me and believing in me.

To Dr. Lee, thank you for taking on the insanity of what has become my dissertation and for providing feedback and encouragement through the process and throughout my $\mathrm{PhD}$. To Dr. Miller, Dr. Hoffman, and Dr. Selden, thank you all for all of your feedback and words of encouragement throughout my degree process and the dissertation process. To Dr. Gottfredson, thank you for all of your help with my data, and to Dr. Komives, thank you for providing the support at work and the dissertation documents that set this project rolling. 
To Dr. Fabian, thank you for taking me on as a young graduate student and mentoring me over the years, I would not be the future Rehabilitation Counselor Educator that I hope to be without your support.

To Ali, thank you for taking the hours and hours to edit my dissertation, listen to me cry, and just be there for me. SmAsh, thank you for the countless running study breaks, office freak-outs, and ridiculous office dance parties. Arifi, thank you for being there for me throughout my time at Maryland, my life would not have been nearly as fun (and survivable) if we hadn't met that fateful day in EDMS 645. Amour/Elibazeth, thank you for all of your support and editing help over the years.

To Trusty's and The Looking Glass, and The Dolphriends, study breaks wouldn't have been the same without you.

I never could have done all of this without the support of the people listed above, among so many more, and I cannot thank those listed enough. The "two-month dissertation" really takes a village, and I feel lucky to have had the support to make something so ridiculous happen. There aren't enough words in the world to express my gratitude. 


\section{TABLE OF CONTENTS}

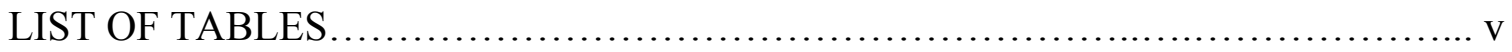

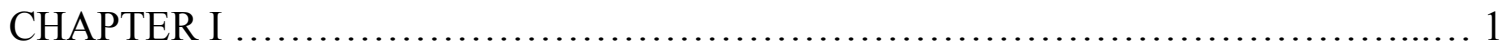

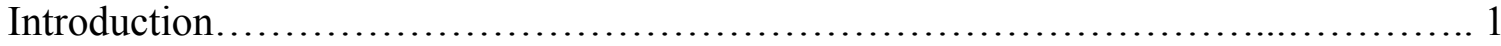

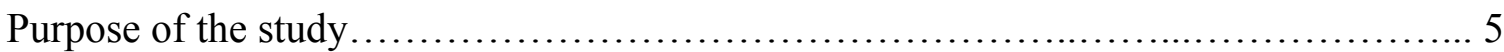

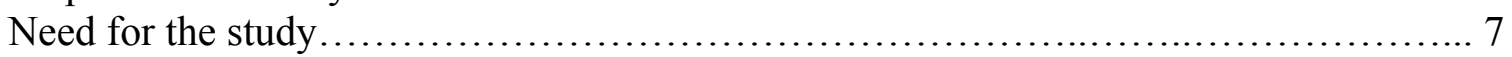

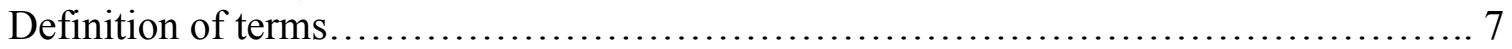

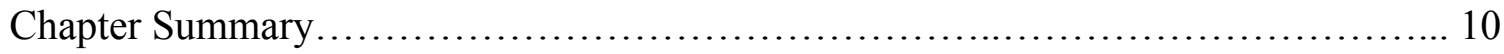

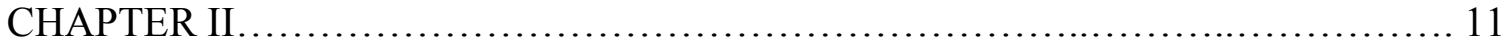

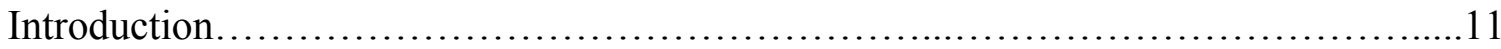

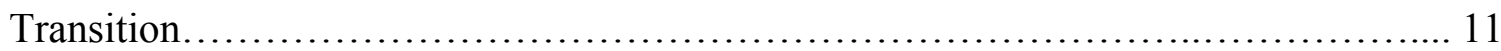

Understanding Transition...................................................... 11

Individuals with Disabilities Education Improvement Act............................. 12

Americans with Disabilities Act................................................ 13

National Alliance for Secondary Education and Transition............................. 14

Barriers to Transition............................................................. 17

Bronfenbrenner's Ecological Systems Theory..................................... 18

Essential aspects of transition.................................................... 19

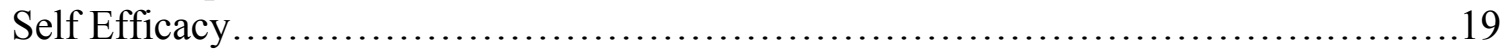

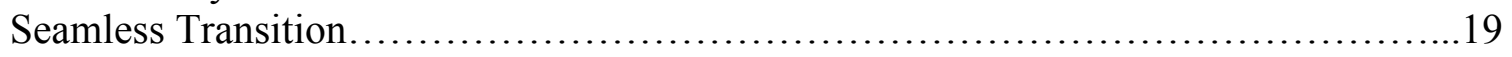

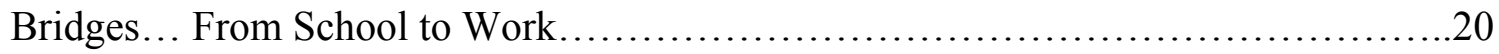

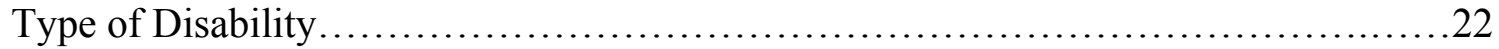

Predictors of Employment.......................................................... 23

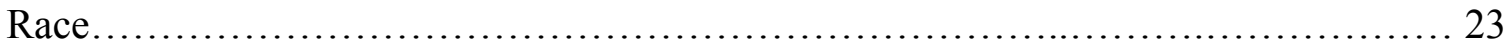

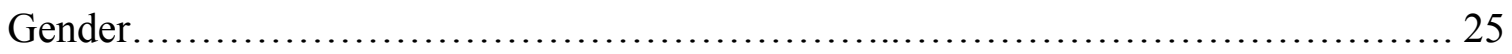

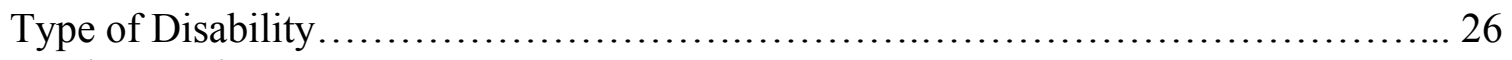

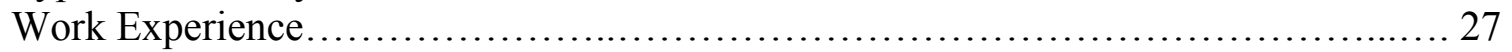

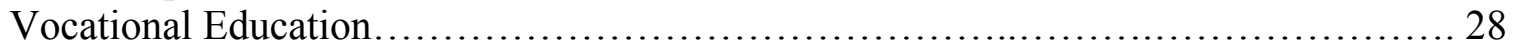

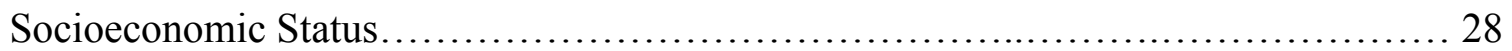

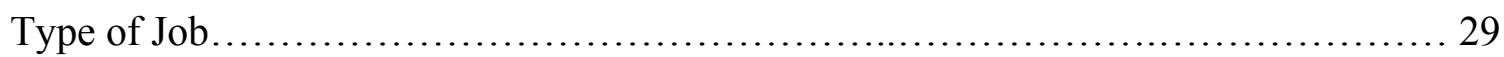

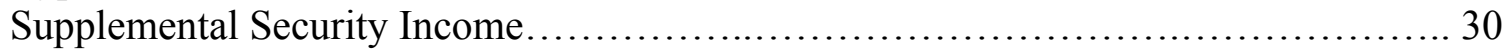

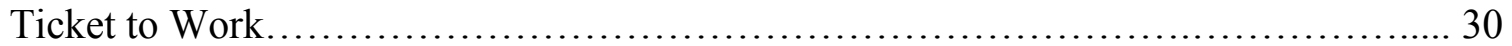

What Leads to Early Termination..................................................... 32

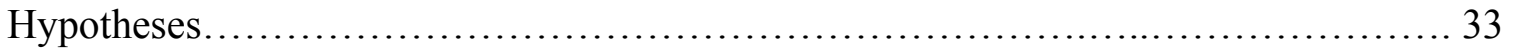

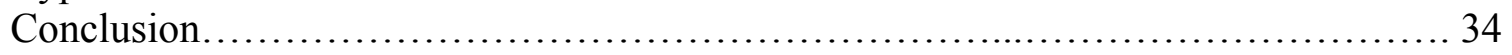

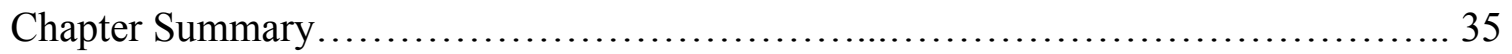

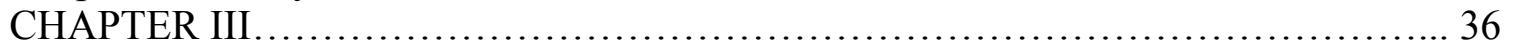

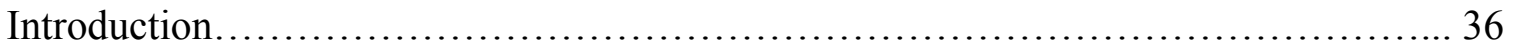

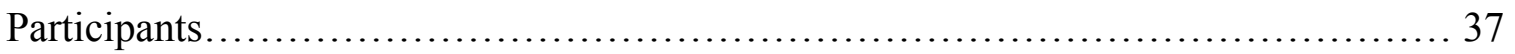

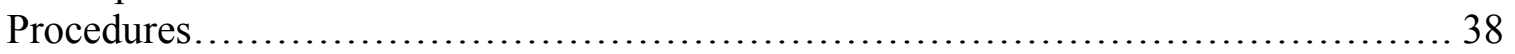

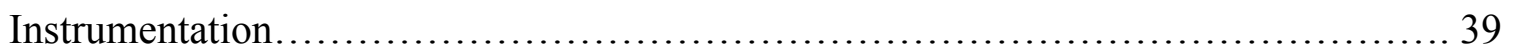

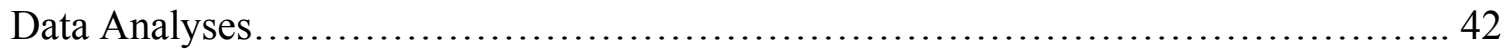

Fully Unconditional Model................................................... 42 
Within Site Model (Level 1) ...................................................... 43

Between Site Model (Level 2) ..................................................... 43

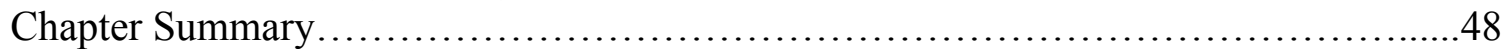

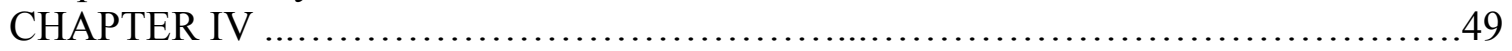

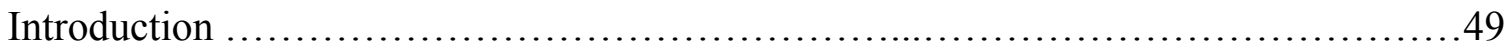

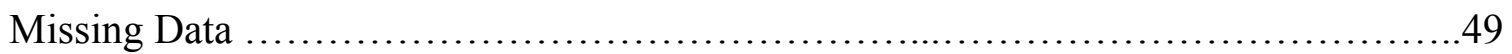

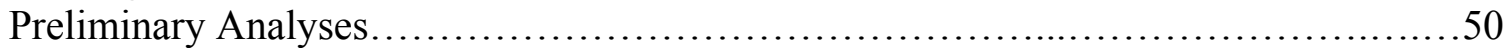

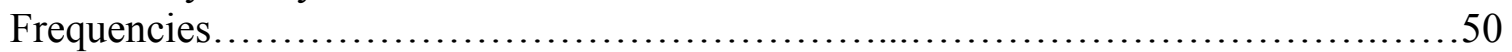

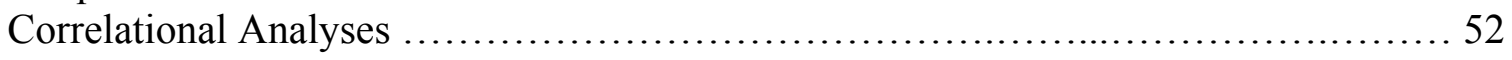

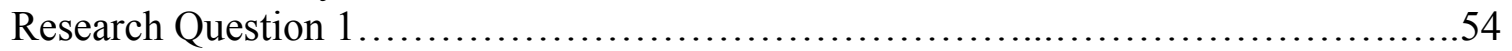

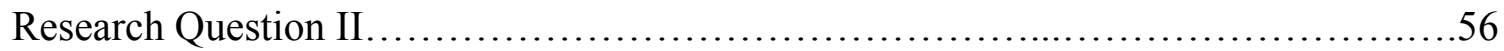

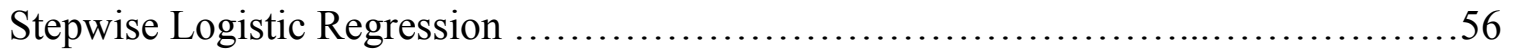

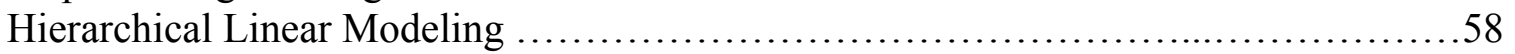

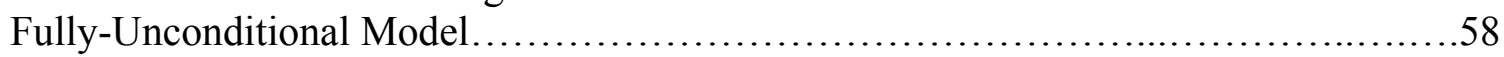

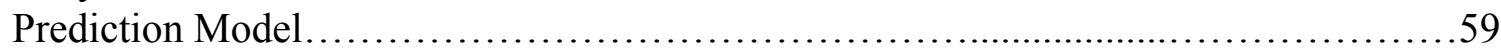

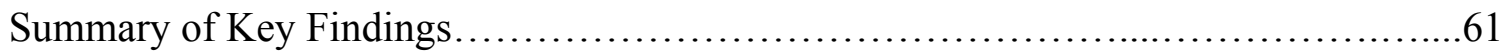

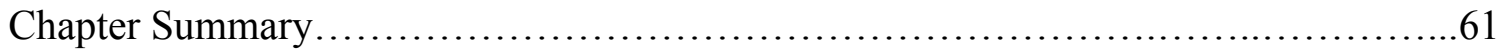

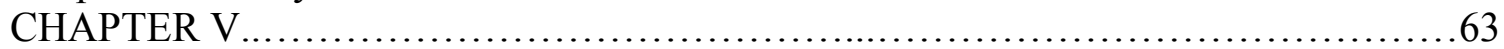

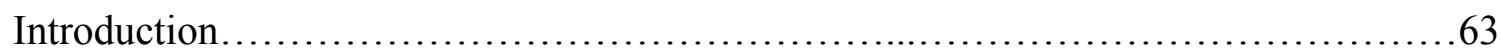

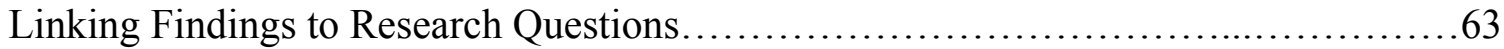

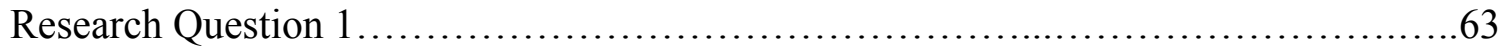

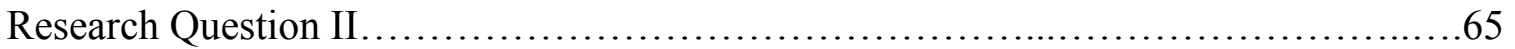

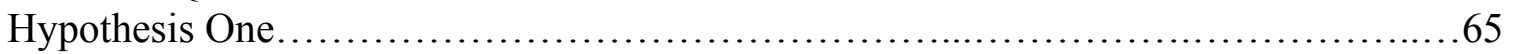

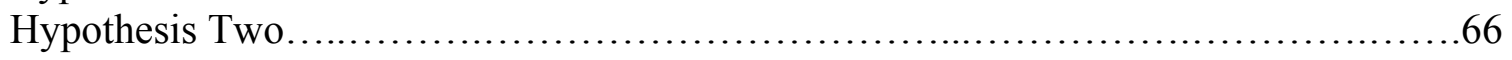

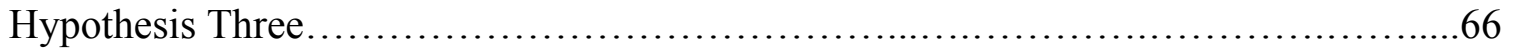

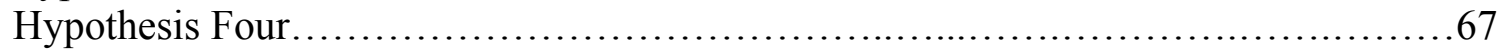

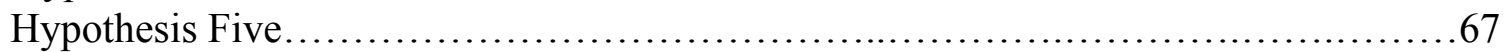

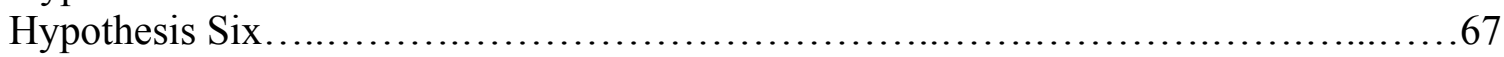

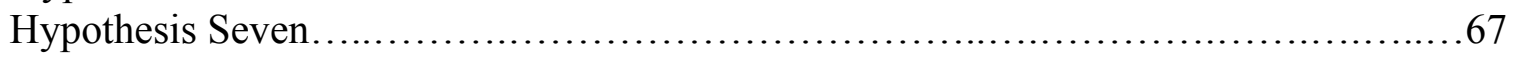

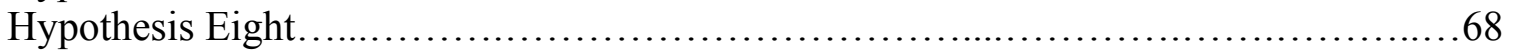

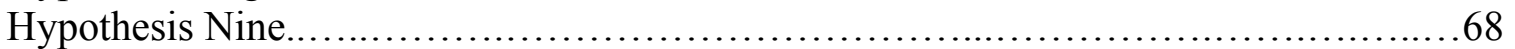

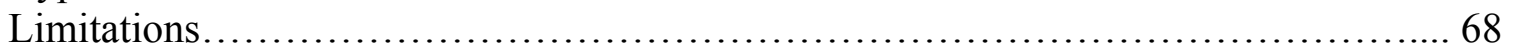

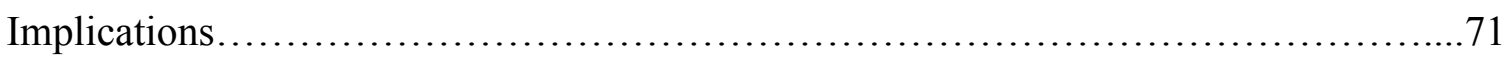

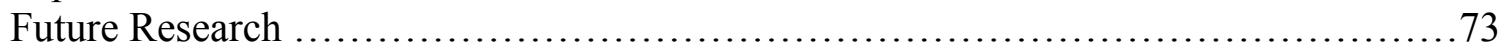

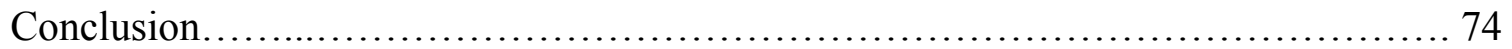

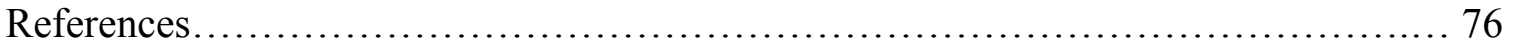




\section{LIST OF TABLES}

Table 3.1. List of independent variables (factors) and percentages of individuals in sample with each factor.

Table 4.1. List of missing data

Table 4.2. List of independent variables (factors) and percentages of individuals in sample with each factor.

Table 4.3. Table of correlations correlating independent variables with early termination

Table 4.4. Table of correlations correlating independent variables with early termination (continued from table 4.3)

Table 4.5. List of reasons for early termination with frequencies

Table 4.6. Results of backward stepwise logistic regression

Table 4.7. Results of Hierarchical Linear Modeling prediction model 


\section{Chapter I}

\section{Introduction}

Post-school outcomes for youth with disabilities continue to lag behind those for youth without disabilities. As of 2010 , only $26 \%$ of youth with severe disabilities in the National Longitudinal Transition Study (NLTS) database were employed (Carter, Austin, \& Trainor, 2011). Additionally, only $66.7 \%$ of all youth with disabilities in the NTLS database had been employed up to eight years post high school as of 2009 (Newman et al., 2011). Over the years, researchers in the rehabilitation counseling field have studied what helps young adults with disabilities obtain and keep employment, what hinders them from obtaining employment, and what services are in place to help them find work. Different conceptual models have been proposed for improving outcomes for youth transitioning from school to work. These differences in approaches to transition may be a contributing factor to the poor post-school outcomes of youth with disabilities (KochharBryant \& Greene, 2009).

The 2011 National Longitudinal Transition Study reported that, eight years post high school, only $66.7 \%$ of young adults with disabilities were working full time or had worked full time in their most recent job. These young adults had a higher unemployment rate (23\%) than the general population of young adults aged 20-24, whose unemployment rate varied from 13.9\% in December 2010 to 15.2\% in December 2011 (Newman et al., 2011; Bureau of Labor Statistics (BLS) 2012). In addition, high school graduates with disabilities earned $\$ 10.61$ per hour, less than half of the 2011 national hourly wage of \$23.19 (Newman et al., 2011; Bureau of Labor Statistics, 2011). 
There are many reasons for the persistently poor post school outcomes of youth with disabilities. Their academic preparation for the job market is inadequate (Benz \& Halpern, 1993; Wagner \& Blackorby, 1996; Wittenburg \& Loprest, 2007), transition planning during high school is uneven (Mason, Field, \& Sawilowsky, 2004), and youth with disabilities have limited participation in career and vocational education curriculum, both of which have been suggested to have positive impact on post-school outcomes (Benz \& Halpern, 1993; Wagner \& Blackorby, 1996; Wittenburg \& Loprest, 2007). In addition, there is a lack of opportunities for transition to outside school programs and services which assist in securing and maintaining a job after school exit (Certo, Luecking, Brown, Courey, \& Belanger, 2008; Certo, et al., 2003; Certo \& Pumpian, 1997; Gerry \& Certo, 1992).

Disability, demographic, and school-related factors also play a role in predicting employment outcomes for these youth (Entwisle, Alexander, \& Olson, 2000; Fabian, 2007; Gardecki, 2001; Hasnain \& Balcazar, 2009; Wagner, Newman, Cameto, Garza, \& Levine, 2005). In the special education and rehabilitation literature, considerable attention has focused on personal, behavioral, and environmental factors that predict or contribute to successful employment (e.g. Colley \& Jamison, 1998; Lindstrom \& Benz, 2002; Wagner \& Blackorby, 1996; Wittenburg \& Loprest, 2007 among many others). However, relatively little attention has been paid to early termination from jobs, from the reasons for early termination to associated personal and environmental factors.

A plethora of research has tried to identify the factors that contribute to youths with disabilities obtaining a job. According to several studies, being either Asian or White, and male is associated with securing a job during and after school exit (Blackorby 
\& Wagner, 1996; Entwisle, et al., 2000; Fabian, 2007; Hasnain \& Balcazar, 2009; Wagner, et al., 2005). Other significant factors include having prior work experience (Colley \& Jamison, 1998; Fabian, 2007; Wagner, et al., 2005), having participated in vocational education (Karpur, Clark, Caproni, \& Sterner, 2005), and having a career goal (Benz, Lindstrom, \& Yovanoff, 2000). In addition, age, sex, stability of home environment, receiving Supplemental Security Income (SSI), staying in high school, and having an employed sibling also affect whether or not youths with disabilities secure a job during their transition from high school (Fabian, 2007; Fabian, Lent, \& Willis, 1998; Gardecki, 2001; Wagner, et al., 2005).

While most of these studies have focused on predicting successful job outcomes, it is important to examine factors and characteristics associated with lack of success. For example, students with emotional/behavioral disabilities, intellectual disabilities, and multiple disabilities are less likely to secure a job (Fabian, 2007; Wagner, et al., 2005), as are Hispanic females (Fabian, 2007). African-American youth living in high poverty neighborhoods with long commutes to work are less likely to have a job prior to school exit (Fabian, 2007; Gardecki, 2001; Hasnain \& Balcazar, 2009).

Services for youths with disabilities are also related to employment outcomes. Vocational education has been found to have a significant impact on whether or not a student with a disability transitions to employment (Colley \& Jamison, 1998; Lindstrom \& Benz, 2002; Wagner \& Blackorby, 1996). However, one study found that only $70 \%$ of students with disabilities were taking even one vocational education class in high school (Newman, 2005). Another study found that students who are female, exhibit more career 
maturity, and perceive higher levels of support and more positive peer attitudes towards school will engage in more career planning activities (Kenny \& Bledsoe, 2005).

While the majority of studies have focused on factors related to getting a job, there are a few that have looked at job retention. Research has shown that a previous paid or unpaid work experience is a significant predictor of job retention (Colley \& Jamison, 1998; Fabian, et al., 1998; Karpur, et al., 2005). Level of education, income, health, and perceptions of disability also had a significant impact on job retention in several studies (Colley \& Jamison, 1998; Fabian, et al., 1998; Hasnain \& Balcazar, 2009).

However, reasons for early job termination have not been well explored in the literature. A study of students with severe emotional disorders found that $46 \%$ of these students were fired from their jobs during their senior year of high school (Benz \& Halpern, 1993). In a study of 63 participants with psychiatric disabilities in supported employment, Becker et al. (1998) found that early job termination was a result of poor interpersonal skills, psychiatric symptoms, work performance, and medical problems. Finally, a 2003 study found discrepancies between supervisor and employee self-rating of employee performance in a sample of 47 adolescent workers with emotional or behavioral disturbances. This was considered a contributing factor to early termination (Carter \& Wehby, 2003).

It is clear from existing research that youth with disabilities have encountered significant difficulties in transitioning from high school to employment. The lack of a unified transition process between high school and post-school employment is part of the problem. Once youth with disabilities exit high school, they are typically referred to 
adult service agencies that have not collaborated with special education programs to design a "seamless" transition for these young adults (Certo, et al., 2003; Hasazi, Furney, \& DeStefano, 1999). Other barriers to successful post-school planning include not having the opportunity to discuss post-school plans with professionals, not being involved in the Individualized Education Plan (IEP) process, and not receiving career development services that assist in transition (Hitchings, et al., 2001; Hitchings, Retish, \& Horvath, 2005; Janiga \& Costenbader, 2002).

However, a number of career development and internship placement programs exist to assist youth with disabilities in transitioning from high school to work. One such program, the Marriott funded Bridges... From School to Work program, has historically been successful in assisting youth with this transition (Marriott Foundation, 2012). Data from this transition program will be utilized in this study.

\section{Purpose of the study}

Although many researchers have studied factors related to youth with disabilities obtaining jobs, few studies have focused on youth who get but do not retain employment. The purpose of this study is to explore what factors contribute to early termination of internships in a school to work transition program.

The research questions guiding this study are as follows:

1. What reasons did youths with disabilities participating in a national multi-site vocational intervention program give for early termination from the program?

2. What personal and programmatic variables (race, gender, per capita income, prior work experience, previous vocational education, job benefits, and whether or not the individual is a Supplemental Security Income (SSI) 
recipient or is utilizing their Ticket to Work (TTW)) contributed to early termination from a job placement program for youth with disabilities?

Based on previous research, the hypotheses of this study are as follows:

Hypothesis 1: Race will have a significant impact on early termination (Blackorby \& Wagner, 1996; Entwisle, et al., 2000; Fabian, 2007; Gardecki, 2001).

Hypothesis 2: Gender will have a significant impact on early termination (Fabian, 2007; Gardecki, 2001).

Hypothesis 3: Type of disability will have a significant impact on early termination (Benz \& Halpern, 1993).

Hypothesis 4: Per Capita Income will have a significant impact on early termination (Fabian, 2007).

Hypothesis 5: Prior work experience will have a significant impact on early termination (Colley \& Jamison, 1998; Fabian, 2007; Wagner, et al., 2005).

Hypothesis 6: Previous vocational education will have a significant impact on early termination (Colley \& Jamison, 1998; Karpur, et al., 2005; Wagner \& Blackorby, 1996).

Hypothesis 7: The presence of job benefits will have a significant impact on early termination (Hasnain \& Balcazar, 2009).

Hypothesis 8: Receiving Supplemental Security Income (SSI) will have a significant impact on early termination (Fabian, 2007).

Hypothesis 9: Utilizing the Ticket to Work (TTW) will have a significant impact 
on early termination.

\section{Need for the Study}

While many researchers have focused on factors that impact youth with disabilities obtaining work (Benz, et al., 2000; Blackorby \& Wagner, 1996; Colley \& Jamison, 1998; Entwisle, et al., 2000; Fabian, 2007; Fabian, et al., 1998; Gardecki, 2001; Hasnain \& Balcazar, 2009; Wagner \& Blackorby, 1996; Wagner, et al., 2005), very few studies have focused on youth with disabilities who obtain but do not retain a job. Identifying factors that contribute to early termination from an internship can be beneficial on many levels. These factors can give counselors and counselor educators insight into special supports or interventions that vocational rehabilitation counselors can provide to at-risk youth with disabilities, helping them to be more successful in their internships. If vocational rehabilitation counselors are aware of the factors that contribute to early termination from work, they can identify at-risk youth with disabilities early on in an internship placement. This can aid vocational rehabilitation counselors in focusing specific interventions for at-risk youth, reducing the likelihood of early termination. This is especially important for at-risk youth because previous work experience has been found to be a significant predictor in employment post-high school (Colley \& Jamison, 1998; Fabian, 2007; Wagner, et al., 2005).

\section{Definition of Terms}

\section{Bridges... From School to Work}

The Bridges... From School to Work program (Bridges program) is an internship program for youth with disabilities that places over 1,000 youth with disabilities in paid 
internships each year. The staff works with youth for 15-24 months, providing job placement and other employment services (Marriott Foundation, 2012).

\section{Early Termination}

For the purpose of this study, early termination is defined as obtaining a paid internship through the Bridges program but not remaining in the internship until successful completion.

\section{Supplemental Security Income}

Supplemental Security Income (SSI) is a benefits system that provides income to qualifying individuals with disabilities. In order to qualify for SSI as a youth, one must have a disability that results in significant functional limitations or is expected to lead to death. This disability cannot be temporary (it will not last under 12 months).

Alternately, an individual who is blind can also qualify for SSI (Social Security Administration, 2011d). In this paper, SSI will also be referred to more generally as Social Security Benefits.

\section{Ticket to Work}

The Ticket to Work (TTW) is a program, which allows individuals with disabilities who receive Social Security disability benefits like SSI to access vocational services from any authorized entity identified in the law as an "Employment Network." This permits individuals to receive job development and placement services from support programs and service providers (like employment networks) that are not state vocational rehabilitation programs. Individuals with disabilities have more autonomy when using the Ticket to Work because they can to choose where to receive employment services (Administration, 2011c). 


\section{Transition}

According to the Individuals with Disabilities Education Improvement Act (IDEA) of 2004, transition is a coordinated set of activities for a child with a disability that:

(A) Is designed to be within a results-oriented process, that is focused on improving the academic and functional achievement of the child with a disability to facilitate the child's movement from school to post-school activities, including post-secondary education, vocational education, integrated employment (including supported employment), continuing and adult education, adult services, independent living, or community participation;

(B) Is based on the individual child's needs, taking into account the child's strengths, preferences, and interests; and

(C) Includes instruction, related services, community experiences, the development of employment and other post-school adult living objectives, and, when appropriate, acquisition of daily living skills and functional vocational evaluation (Individuals with Disabilities Education Improvement Act, 2004).

\section{Work}

For the purpose of this paper, work is defined as an internship or job that results in hourly pay for the youth with a disability. 


\section{Chapter Summary}

This chapter has introduced the existing research on employment for youth with disabilities, highlighting the paucity of research into why youth with disabilities terminate work early. It also outlined the purpose of the study, its research questions and hypotheses, and key terms to be used in the study. 


\section{Chapter II}

\section{Literature Review}

This chapter focuses on transition from a legislative view, as well as from the perspective of a coalition of organizations that assist youth with disabilities in their transition from high school to work. Two popular models of transition are discussed, followed by an overview of the known predictors of employment. These include race, gender, disability type, socioeconomic status, work experience, vocational education, SSI, and the TTW. The chapter concludes with an explanation of the study's hypotheses.

\section{Transition}

\section{Understanding Transition}

In order to understand the concept of transition for youth with disabilities, it is important to first note the barriers that individuals with disabilities have faced in education and work. Individuals with disabilities faced severe discrimination in the workplace for much of U.S. history. The only mandate related to employment for individuals with disabilities was section 504 of the Rehabilitation Act of 1973, prohibiting government-funded employers from discriminating against individuals with disabilities. However, individuals working for employers who did not receive government funding continued to have no legal recourse for discrimination in the workplace on the basis of their disability (Mayerson, 2006). Things began to change when the Americans with Disabilities Act (ADA) of 1990 was signed into law, mandating that employers provide reasonable accommodations to employees with disabilities. 
For youth with disabilities, laws regarding education for children with disabilities were virtually nonexistent prior to 1975 . The first special education law, the Education for All Handicapped Children Act of 1975, mandated free and accessible public education for all children with disabilities (ed.gov, 2000). In 2004, the Education for All Handicapped Children was reauthorized as the Individuals with Disabilities Education Improvement Act (IDEA). IDEA continued to require free and equal access to public education for students with disabilities. It also added a number of mandates designed to improve educational and transition services for children and youth. Both the ADA and IDEA are discussed in more detail in the following section, with a focus on two popular transition models that fit the transition services the IDEA mandates for youth with Individualized Education Programs (IEPs).

Individuals with Disabilities Education Improvement Act. The IDEA, similar to previous re-authorizations of special education laws, required that students with disabilities have IEPs. These IEPs should be collaboratively developed by educational personnel, families, students, and other related service personnel such as psychologists, rehabilitation counselors, and other professionals (Mason, et al., 2004). The IEP includes a plan for education, developed as soon as the student has been determined eligible for services, as well as a transition plan, developed by age 16 . The transition plan must include “(aa) ...training, education, employment, and, where appropriate, independent living skills, (bb) the transition services... needed to assist the child in reaching those goals..." (Individuals with Disabilities Educaton Improvement Act, 2004).

Under IDEA, children with disabilities are guaranteed academic accommodations that are determined through the needs assessment in their IEP. However, as these 
children become young adults and are no longer eligible for IDEA, receiving accommodations becomes a more challenging process. An individual with a disability who looks for or secures a job is protected under the ADA, but legal protection from discrimination and reasonable accommodations are not provided automatically in the workplace as they were in school. This change is a significant one, as youth with disabilities must become advocates for themselves in order to request and receive accommodations in the workplace.

Americans with Disabilities Act. The ADA was passed in 1990 and amended in 2009 (U. S. Census Bureau, 2009). It was primarily enacted to mandate nondiscrimination in employment and other settings, as well as to ensure that people with disabilities had equal access to private and public services and settings. This study focuses on Title 1 of the ADA, which prohibits discrimination in employment. It also requires that employers provide reasonable workplace accommodations for qualified individuals with disabilities, enabling them to perform the essential functions of a job. In order to receive accommodations at work, individuals must disclose and document the presence of a disability. Doing so entitles them to protection under the ADA, including the provision of reasonable accommodations.

There is a considerable difference between requesting workplace accommodations under the ADA and requesting academic accommodations under IDEA. With the IDEA, it is frequently educators and specially trained personnel who identify an academic need and the resource or service required to address it. When documenting the presence of a disability according to the provisions of the ADA, it is typically the responsibility of the individual requesting the accommodation to identify what is needed. This difference is 
where service providers and other professionals who work with individuals with disabilities to assist them with employment activities may be especially helpful. Service providers can train youth with disabilities on what their rights are in the workplace, guide them in how to request an accommodation, and even request accommodation on their behalf.

Encouraging service providers to work with special education students prior to school exit has been difficult. This lack of collaboration can result in young adults with disabilities falling through the cracks upon school exit (Certo, et al., 2003). It may also be part of the reason why, in one study, only $26 \%$ of young adults with disabilities had requested accommodations in the workplace (Newman, Wagner, Knokey, Marder, Nagle, Shaver, \& Wei, 2011). However, service providers in transition programs can assist youth with disabilities in the accommodation request process. This action can be instrumental to youth requesting and receiving accommodations in the workplace.

National Alliance for Secondary Education and Transition. Formed in 2003, the National Alliance for Secondary Education and Transition (NASET) is a coalition of school counseling organizations, rehabilitation counseling organizations, and education and post-secondary education organizations. NASET includes over 30 organizations and the goal of the coalition is to:

1. Identify what youth need in order to achieve successful participation in postsecondary education and training, civic engagement, meaningful employment, and adult life; and 2. Prioritize and address significant issues of national scale that have an impact on the development of appropriate policies and 
the provision of effective secondary education and transition

services for all youth (National Alliance for Secondary

Education and Transition, 2010).

Through the collaboration of multiple organizations, NASET has developed transition standards to help ensure the efficacy of transition programs for youth with disabilities (National Alliance for Secondary Education and Transition, n.d.) These standards, developed from relevant transition literature, include recommendations that transition programs include:

1. Schooling;

2. Career preparatory experiences;

3. Youth development and youth leadership;

4. Family involvement; and

5. Connecting activities

In addition to these recommendations, NASET provides transition programs with a self-assessment tool, which utilizes behavioral indicators to determine how programs are meeting NASET standards. The organization offers an additional tool which assists transition programs in determining what their priorities are, as well as an outline to help them develop an action plan which meets the NASET standards (National Alliance for Secondary Education and Transition, n.d.). Because inconsistencies in transition approaches may contribute to the poor post-school outcomes of individuals with disabilities, these standards and tools can help create more successful transition approaches through standardization (Kochhar-Bryant \& Greene, 2009). 
Schooling. NASET schooling standards state that education should prepare students for post-school life. Youth with disabilities should be educated and assessed using the general curriculum, with the educational system providing accommodations for the student based on their disability, to prepare them to enter the work world. In addition, schools should implement systems that encourage school completion and lower the dropout rate for youth with disabilities. Finally, educators should have an understanding of the transition process and should be aware of the unique needs of youth with disabilities in transition (National Alliance for Secondary Education and Transition, n.d.).

Career preparatory experiences. NASET also suggests that youth with disabilities be given the opportunity to participate in career development during the transition process. This includes career guidance and career education. In addition, the coalition recommends that youth with disabilities have the opportunity to participate in community based work experiences, as well as to gain knowledge and skills that will better prepare them for the workforce (National Alliance for Secondary Education and Transition, n.d.).

Youth development and youth leadership. Youth with disabilities should be given the opportunity to participate in community life so that they may gain leadership skills through these experiences (National Alliance for Secondary Education and Transition, n.d.). These opportunities can help youth with disabilities to learn about their skills and strengths. It can also aid them in developing the ability to self-advocate, increasing the likelihood that they request workplace accommodations in future. Participation in the community can also give students an opportunity to gain self-determination skills, which can lead to positive post-school outcomes in goal setting, employment, financial 
independence, and independent living (Agran \& Wehmeyer, 2000; Wehmeyer \& Palmer, 2003; Wehmeyer \& Schwartz, 1998).

Family involvement. According to NASET and many other researchers and transition programs (e.g. Wehmeyer, Agran, \& Hughes, 1998), family involvement is very important in the transition process. Transition programs should include the family in the process, and should assist the school in developing collaborative relationships with youth and their family. Additionally, youth and their family should be included in the process of formulating an IEP and within that process, the transition plan, which is both mandated by IDEA and considered a best practice by transition experts (ed.gov, 2000; Wehmeyer, et al., 1998).

Connecting activities. Connecting activities should be actively pursued, such as building collaborative relationships between service providers and youth. These collaborative partnerships should include individuals who are well versed in transition and capable of properly and knowledgably assisting youth in the transition process.

Barriers to transition. Despite the specification of transition related standards and the legislation supporting transition to work for youth with disabilities, labor statistics show that they continue to encounter challenges in attempting to secure a job. A number of reasons for the persisting challenges have been suggested, and a great deal of research has focused on identifying them. Many studies have examined the effect of demographic and disability factors on work, finding that race (Blackorby \& Wagner, 1996; Entwisle, et al., 2000; Fabian, 2007; Gardecki, 2001), gender (Fabian, 2007; Gardecki, 2001), and type of disability (Fabian, 2007; Wagner, et al., 2005) have an impact on youth with disabilities procuring employment. Several studies have examined 
the influence of contextual factors on work outcomes, such as vocational or career education (Colley \& Jamison, 1998; Lindstrom \& Benz, 2002; Wagner \& Blackorby, 1996), previous work history (Benz, et al., 2000; Colley \& Jamison, 1998; Fabian, 2007), and type of special education services received (Wagner \& Blackorby, 1996). More recently, studies have examined psychosocial attributes and their influence on work, such as self-determination (Agran \& Wehmeyer, 2000; Wehmeyer, et al., 1998; Wehmeyer \& Palmer, 2003) and self-efficacy (Wehmeyer, 1999). It is essential to keep these barriers to transition in the forefront of transition discussions, so that researchers better understand how these difficulties impact the transition process for youth with disabilities.

Bronfrenbrenner's Ecological Systems Theory. Bronfrenbrenner's Ecological Systems Theory relates closely to the topic of this dissertation due to its hierarchical nature. Bronfenbrenner's theory consists of five environmental systems which each speak to a different level of interaction with the individual (Bronfenbrenner, 1989). The theory specifies the microsystem (for example: the child's family, peers, school, neighborhood, etc.), the exosystem (for example: social setting, neighbors, legal services, social services, etc), the macrosystem (the culture in which the child lives), the chronosystem (environmental events that occur during the child's development), and the mesosystem (the way the microsystem, exosystem, macrosystem, and chronosystem relate to one another). For a youth with a disability in transition, for example, a transition program would be part of the microsystem (the school) as well as the macrosystem (the external transition program) as well as the mesosystem (how the school and the transition program relate to one another). Barriers to transition could lie at any level of the model (e.g. barriers stemming from being a Middle Eastern youth with a disability in the months 
after $9 / 11$ would be related to the macrosystem - culture and chronosystem - 9/11).

Bronfenbrenner's Ecological Systems Theory can provide a solid conceptual framework for research on youth with disabilities (Sontag, 1996).

\section{Essential Aspects of Transition}

In addition to an understanding of standards and best practices in transition, it is important to be familiar with concepts of transition as well as currently implemented models of transition to better understand the Bridges transition program from which the data for this study is drawn. The following section describes the importance of selfefficacy in transition followed by two models of transition: the Seamless Transition model and the Bridges model.

Self-Efficacy. The concept of self-efficacy is the theory that how people perceive themselves and what they accomplish are interrelated, and those beliefs affect how they perform (Bandura, 1994). The concept of self-efficacy for youth with disabilities has been studied in a number of venues. For example, research has shown that having previous vocational experience is related to higher levels of self-efficacy (Benz \& Halpern, 1993; Hackett \& Bryars, 1996; Wehmeyer, 1999). In addition, involvement in the transition process (for example being involved in IEP meetings) has been shown to increase the self-efficacy of youth with some disabilities (Wehmeyer \& Lawrence, 1995). This demonstrates the importance of self-efficacy within the transition process.

Seamless transition. In order to reduce the likelihood that students fall through the cracks during the transition process, Certo et al. (2003) proposed a transition model that provides services beginning in high school and continuing post-graduation. This "seamless transition" approach focuses on coordinating vocational services between 
schools, the transition program, the family, and stakeholders while youth with disabilities are still in school. Such coordination ensures that each student exits high school with a job and a career plan, including the identification of specific community-based career services. In their final year of high school, students receive vocational instruction and support at school and at the local one-stop career center. After exiting high school, students continue to receive support at the career center. A study of 234 youth with disabilities conducted by Certo et al. (2003) found that this approach helped $88 \%$ of high school graduates to maintain a job after school exit. Additionally, $90 \%$ of the participants continued receiving services up to three years post graduation from the same agencies they had worked with while in school.

Because of the success of the seamless or collaborative transition approach (Certo, et al., 2003; Luecking \& Certo, 2002; Sax, Noyes, \& Fisher, n.d.), this study utilizes the approach in creating a model that extends transition services to youth with disabilities. The model is based on an existing, highly successful, seamless approach to transition: the Bridges program.

Bridges... From School to Work. The Bridges program is a non-profit transition program for students with disabilities that was developed by the Marriott Foundation in 1989 (Marriott Foundation, 2008). The goal of the program is to assist students with disabilities transitioning out of high school to find and retain competitive employment. Each year, the program places over 1,000 youth with disabilities in competitive employment during their transition process (Marriott Foundation, 2012). Between 1990 and 2009, the Bridges program assisted more than 16,500 transitioning students and placed 12,000 students in competitive employment with over 3,500 
companies. The Bridges program currently serves students at eight urban inner city sites in Atlanta, Chicago, Dallas, Los Angeles, Philadelphia, San Francisco, Oakland, and Washington, DC.

The Bridges program focuses on both the student and the employer. In order to ensure the satisfaction of the employer, the program focuses on employer needs and ensures that they are met. In addition, the program places students in positions where the individual's strengths match with the job description, so that limitations do not greatly affect the job. This model has been successful for the Bridges program, with employers using the Bridges program to hire multiple students with disabilities (Marriott Foundation, 2012).

In order to be eligible for the program, the student must first be work eligible, such as holding a social security card or other proof of work eligibility. Students must also demonstrate that they have a disability through documentation, which can take the form of an IEP from their school, documentation from a medical professional, or documentation of their disability from a state vocational rehabilitation office (Marriott Foundation, 2012).

The program assists students in transition (ages 17-22) in three steps. The first step is career counseling and job placement. This is followed by the second step, a paid work experience during which the participants receive support from Bridges staff. Finally, the Bridges program provides the third step of follow-up services, tracking the students after they exit the program (Fabian, 2007). The ultimate goal of the program is for students to get a job prior to leaving high school and sustain it after graduation. The Bridges program is a highly standardized intervention with specific program 
implementation guidelines, staff training, and ongoing monitoring and review by the central headquarters staff at the Marriott Foundation in Bethesda, Maryland. It is funded through a variety of sources, including private businesses and state and federal contracts and grants (Marrriott Foundation, 2012).

The Bridges program utilizes several best practice approaches to transition. The program builds collaborative relationships with schools, workforce agencies, and vocational rehabilitation systems. In addition, participants enter the program at age 17. These are considered best practices in approaches to transition, from both a seamless transition perspective and the NASET standards (Certo, et al., 2003; Transition, 2010).

Type of Disability. Many researchers have studied the impact of the type of disability an individual has on their gaining employment. Fabian's (2007) study, which used the Bridges database, found significant differences in job placement based on types of disabilities. Youth with orthopedic impairments were the least likely to be placed in a job, with $55 \%$ not placed, followed by youth with hearing impairments, $42 \%$ of whom were not placed. Approximately $30-33 \%$ of youth with learning disabilities, emotional or behavioral disorders, mental retardation, visual impairments, chronic health impairments, and speech or language impairments were not placed in jobs.

Using the National Longitudinal Transition Study-2, Wagner et al. (2005) found that youth with learning disabilities were the most likely to be employed, at a rate of $54 \%$, followed by $49.4 \%$ of those who had sustained a traumatic brain injury. Youth with emotional disturbances had an employment rate of $43.8 \%$, followed by youth with other health impairments, multiple disabilities, speech or language impairments, mental retardation, orthopedic impairments, hearing impairments, and autism (in that order). 
Youth with autism were the least likely to be employed; only $14 \%$ of those youth had obtained employment. Fabian's (2007) study contained slightly contradictory results, which is likely due to the fact that these two studies had divergent disability categories.

Although there is some contradiction between these studies, both show significant differences in employment based on type of disability. Wagner et al. (2005) found higher employment rates for youth with learning disabilities, while the lower rates in Fabian's (2007) study indicate a need for further exploration of employment for youth with disabilities.

\section{Predictors of Employment}

\section{Race}

The impact of race has long been considered a predictor of employment. Many studies have found that minority youth are less likely to obtain employment (D'Amico, 1984; Entwisle, et al., 2000; Gardecki, 2001; Ihlanfeldt, 1992; O'Regan \& Quigley, 1996), and this remains true for minority youth with disabilities (Blackorby \& Wagner, 1996; Fabian, 2007). In order to understand the barriers that minority youth with disabilities face when seeking and obtaining work, it is important to look at these differences in the general population.

In 1984, D'Amico conducted a study using data from the National Longitudinal Surveys of the Labor Market Experience of Youth. The study found significant differences in employment rates for White youth versus minority youth. Over $46 \%$ of White youth were employed for at least one week during high school, while only $32 \%$ of minority youth were employed at the same level. 
Ihlanfeldt (1992) looked at U. S. Department of Labor data comparing the unemployment rate of Black and White male teenagers. He found that the unemployment rate changed drastically between 1950 and the 1980s. In the early 1950 s, the unemployment rate for Black and White male teenagers was virtually the same. However, the unemployment rate for White male teenagers has remained the same over the last 30 years, while the rate for Black male teenagers has risen dramatically. By the early 1990s, White male teenagers were almost twice as likely to have a job as Black male teenagers.

A large-scale study conducted by Entwisle, Alexander, and Olson (2000) collected longitudinal data from a study of 790 children in the Baltimore Public School System. By the time students reached the age group of $15-18$, only $81 \%$ of the sample (640 students) remained, due to attrition that often occurs within longitudinal studies. When comparing the data from when youth entered the study to the current data, it was determined that attrition was not a significant limitation. The authors compared the job seeking activities of White students and African American students. While African American students reported conducting job-seeking activities at an equal or greater rate than White students, they were less likely to be employed than their White counterparts.

Just as minority youth lag behind White youth in employment, youth with disabilities have far higher unemployment rates than youth without disabilities (Blackorby \& Wagner, 1996). This makes a discussion of the employment rates of minority youth with disabilities essential, as they may encounter both race and disability discrimination in employment. In 1996, Blackorby and Wagner utilized data from the National Longitudinal Transition Study, which surveyed over 8,000 youth in transition 
aged 13-21. The study contained data on 1,900 youth in transition who had exited high school, either through graduation or dropping out. The study found that African American youth with disabilities had an employment rate of $47 \%$, significantly lower than the $67 \%$ rate of their White counterparts. This disparity extended to Hispanic youth with disabilities, who had approximately a 50\% employment rate.

In 2007, Fabian utilized data from the Bridges program to determine what factors impacted youth with disabilities obtaining work. The study utilized youth who participated in the transition program from 2000 to 2005 , resulting in a sample of 4,571 . She found that Hispanic females were the least likely to obtain work of any minority group. In addition, African American and Latino youth were less likely to obtain work than White or Asian youth, regardless of gender.

Understanding the implications of race in employment is essential to understanding factors that influence the employment of youth with disabilities. While there is an important difference between obtaining employment and early termination, it is impossible to view early termination in a vacuum. The significantly different employment rates of White and minority youth with disabilities may help to explain the role that race plays in early termination rates.

\section{Gender}

Researchers have also found differences in employment rates based on gender. In 2009, Hasnain and Balcazar conducted a study utilizing the U. S. National Health Interview Survey on Disability data (originally collected between 1994 and 1995), which included 1,899 youth with disabilities ages 18-26. While the study focused on whether or not youth with disabilities obtained work in the community or a facility-based setting, it 
had important findings on gender differences. Females with disabilities were less likely to be employed in a community based setting, indicating differences in employment between males and females with disabilities. This was also true for minority youth with disabilities, with White youth less likely to be placed in a facility-based setting.

Two of the studies described in the previous section on race also found differences in employment rates based on gender. Fabian's (2007) study, which found that Hispanic females were the least likely minority and gender group to obtain work, also discovered that females were less likely to obtain employment than males. The D'Amico study (1984) found that women earned, on average, over 50 cents less than males. However, the author found male employment rates to be only marginally higher than rates for females. Similarly, Blackorby and Wagner (1996) found that males with disabilities earned more than females with disabilities. Interestingly, Gardecki's (2001) study found that females were more likely to be employed than males. However, the study focused on the general population of youth, not youth with disabilities. Overall, disparities in employment based on gender make the inclusion of the variable essential to this study.

\section{Type of Disability}

Many researchers have studied the impact of the type of disability an individual has on their gaining employment. Fabian's (2007) study, which used the Bridges database, found significant differences in job placement based on types of disabilities. Youth with orthopedic impairments were the least likely to be placed in a job, with 55\% not placed, followed by youth with hearing impairments, $42 \%$ of whom were not placed. Approximately $30-33 \%$ of youth with learning disabilities, emotional or behavioral 
disorders, mental retardation, visual impairments, chronic health impairments, and speech or language impairments were not placed in jobs.

Using the National Longitudinal Transition Study-2, Wagner et al. (2005) found that youth with learning disabilities were the most likely to be employed, at a rate of $54 \%$, followed by $49.4 \%$ of those who had sustained a traumatic brain injury. Youth with emotional disturbances had an employment rate of $43.8 \%$, followed by youth with other health impairments, multiple disabilities, speech or language impairments, mental retardation, orthopedic impairments, hearing impairments, and autism (in that order). Youth with autism were the least likely to be employed; only $14 \%$ of those youth had obtained employment. Fabian's (2007) study contained slightly contradictory results, which is likely due to the fact that these two studies had divergent disability categories.

Although there is some contradiction between these studies, both show significant differences in employment based on type of disability. Therefore, it is essential to attend to these differences when examining potential factors of early termination.

\section{Work Experience}

Many studies have demonstrated the impact of work experience on post-high school employment (Benz, et al., 2000; Colley \& Jamison, 1998; Fabian, 2007; Fabian, et al., 1998). In 1998, Colley and Jamison studied 720 students with disabilities who had transitioned from high school. They found that having work experience during the transition process led to more positive post-high-school work outcomes for students. In the same year, Fabian, Lent, and Willis used the Bridges program data to study the impact of internship completion on post-high school employment. Using a sample of

over 2,000 students, they found that aspects of the internship, such as hours worked and 
level of job support, were predictors of program completion. Fabian's 2007 study found that internships and other prior work experience increased the likelihood of employment. In a study of 709 youth with disabilities in Oregon, Benz, Lindstrom, and Yovanof (2000) learned that students who held two or more jobs while participating in youth transition programs were almost twice as likely to be employed post-high school than those who had not been employed previously. Because previous work experience and successful internship completion has been associated with positive post school outcomes, the high early termination rates from internships become particularly troubling.

\section{Vocational Education}

Using the National Longitudinal Transition Study of Special Education Students

database, Wagner and Blackorby (1996) found that youth with disabilities who completed vocational courses in high school were more likely to be employed three to five years post-high school. In addition, these youths made an average of $\$ 1,851$ more per year than those who did not participate in vocational edcuation. Colley and Jamison's 1998 study also found that youth who received vocational education had more positive postschool outcomes.

\section{Socioeconomic Status}

Fabian's (2007) study determined that youth from households with incomes below the national average were slightly more likely to be placed through a job placement program than those who lived in more affluent communities. Additionally, she found that the average hourly wage for the youth studied was $\$ 6.91$ per hour. This wage was only slightly above the 1997-2006 minimum wage of $\$ 5.15$, which increased to \$5.85 in 2007 and \$7.25 in 2009 (U. S. Department of Labor, 2010). The link between 
earning disparities and household income demonstrate the importance of including socioeconomic status in a study of early termination.

\section{Type of job}

Hourly earnings relate to both socioeconomic status and the type of job a youth holds. Primary sector jobs are those that give the employee benefits, higher wages, better working conditions, and increased stability in employment. Secondary sector jobs are those with lower wages, fewer or no benefits, and little to no job security (Berger \& Piore, 1980). These sector differences are especially relevant for youth with disabilities, as research shows that spending a period of time in the secondary sector of the job market often permanently relegates individuals to jobs in this sector (Waddoups \& Assane, 1997).

Both female youth with disabilities and minority youth with disabilities were more likely than their privileged counterparts to be placed in a facility-based work setting (Hasnain \& Balcazar, 2009). However, facility-based employment (also referred to as sheltered workshops) is no longer considered a successful employment outcome for youth with disabilities (Boeltzig, Timmons, \& Butterworth, 2008). This is because facility-based employment is part of the secondary labor market. Individuals in facilitybased employment are often paid below minimum wage, although they tend to have more job security than in other secondary labor market jobs (Milgore, Mank, Grossi, \& Rogan, 2007).

There is a trend in rehabilitation counseling of placing individuals with disabilities, especially those with developmental disabilities, in facility-based employment (Braddock, Hemp, \& Rizzolo, 2005), despite the fact that it is not 
considered a successful employment outcome for individuals with disabilities (Boeltzig, et al., 2008). Because workers in secondary labor markets tend to have less stable employment, participation in the secondary labor market could be a reason for early termination for youth with disabilities.

\section{Supplemental Security Income (SSI)}

In November, 2011, about 1.28 million children under the age of 18 were receiving SSI from the U.S. Government (Social Security Administration, 2011b). Fabian's (2007) study found that youth receiving SSI were less likely to obtain employment. This is consistent with other research on SSI Recipients (Berry, 2000). Data from the National Health Interview Survey on Disability showed that recipients of SSI were less likely to have ever worked than those who were not receiving benefits. They were also less likely to be currently working. This is particularly notable because previous employment is one of the strongest predictors of future employment (Benz, et al., 2000; Colley \& Jamison, 1998; Fabian, 2007). As a result, the impact of receiving SSI on early termination should be studied.

\section{Ticket to Work (TTW)}

While there are a number of government programs that can assist people with disabilities in returning to work, one program authorized through the Ticket to Work and Work Incentives Improvement Act of 1999 (TTWWIIA) stands out. TTWWIIA is applicable to SSI beneficiaries aged 18-65 and can be a valuable source of financial assistance for collaborative transition programs. SSI, which includes cash benefits and access to federal health care programs, is provided to eligible people with disabilities who must document the significant barriers to work which result from their disabilities (Social 
Security Administration, 2011a). The TTWWIIA amended the Social Security Act (originally enacted in 1935) to promote competitive work for Social Security beneficiaries. Competitive work is work in the labor market for which an individual with a disability receives pay that meets or exceeds the financial benefits the individual is eligible for. Prior to TTWWIIA, federal Vocational Rehabilitation (VR) agencies were the only public service providers for beneficiaries, and they were limited in their service capacity due to large case loads, limited funding, and a temporary approach to rehabilitation (Pumpian, Fisher, Certo, \& Smalley, 1997; Syzmanski, Hanley-Maxwell, \& Asselin, 1992). The TTWWIIA amendments enable beneficiaries to "purchase" vocational rehabilitation services from a wide range of providers, referred to as "Employment Networks" (ENs). This has considerably expanded the pool of vocational service providers beyond federal VR agencies.

Eligible beneficiaries receive a Ticket to Work (TTW) in the mail and they can utilize the Ticket to Work at any EN they choose, giving them more autonomy in the rehabilitation process. TTW reimburses ENs at varying levels based on the services provided. While utilizing the TTW, individuals with disabilities can delay the continuing disability reviews mandated under SSA law. These reviews are conducted by Social Security Administration employees to determine whether an individual continues to have a significant disability and is therefore still eligible for benefits. With the TTW, individuals remain eligible for benefits so as long as they continue to make progress towards their employment goals. Through TTWWIIA, individuals can continue to receive cash benefits and remain eligible for Medicaid, because being able to work does not automatically exclude an individual from retaining Medicaid benefits. This program 
promotes work for individuals with disabilities, and may mediate the effect of receiving SSI on early termination. However, the lack of participation in the TTW program may also cause these differences to be negligible.

\section{What Leads to Early Termination}

Unfortunately, reasons for early job termination have not been well explored in the literature. A study with a sample of 422 students with disabilities found that $46 \%$ of students with emotional disorders were fired from their jobs during their senior year of high school (Benz \& Halpern, 1993). Additionally, in a study of 63 participants with psychiatric disabilities in supported employment, Becker et al., (1998) found that early job termination was the result of poor interpersonal skills, psychiatric symptoms, work performance, and medical problems. Another study found discrepancies between supervisor and self-rating of employee performance in a sample of 47 adolescent workers with emotional or behavioral disturbances. These discrepancies were considered a contributing factor to early termination (Carter \& Wehby, 2003).

As has been shown, there are a number of factors associated with youths with disabilities securing a job and retaining it. However, few studies have examined reasons for early termination and the individual and environmental factors associated with it. This study is interested in examining a sample of youth participating in a national multisite intervention, to uncover the reasons for early termination and the factors contributing to it. The goal of this analysis is to better understand what interventions are needed for at-risk youth, to ensure program completion and increase post-transition participation in the labor market with positive work outcomes. 


\section{Hypotheses}

This study intends to explore two main ideas related to early termination. First, it is necessary to look at the reasons individuals with disabilities give for terminating early from a job placement program for youth with disabilities. It is also critical to explore the personal and programmatic variables that contribute to early termination from the placement program. This research is especially important because very few researchers have studied early termination from work of youth with disabilities, and successful internship completion can lead to better post-high school outcomes for youth with disabilities (Fabian, 2007).

The first three hypotheses in this study relate to individual predictors of early termination (race, gender, and socioeconomic status). Hypothesis one, that race will have a significant impact on early termination, is posited because previous studies have found race to be a significant predictor in obtaining work (Blackorby \& Wagner, 1996; D'Amico, 1984; Entwisle, et al., 2000; Fabian, 2007; Gardecki, 2001; Ihlanfeldt, 1992; O'Regan \& Quigley, 1996). While existing research is specific to obtaining work, this factor may also contribute to early termination and should be studied. Hypothesis two, which conjectures that type of disability will have a significant impact on obtaining a job, has been supported (Fabian, 2007; Wagner, et al., 2005), necessitating its inclusion in a study on early termination. Socioeconomic status has been shown to have an impact on employment (Fabian, 2007), which is why it is included in this study.

The last five hypotheses are related to variables describing work experience and the job placement the individual receives, as well as external factors (receiving SSI and utilizing the TTW). Both previous work experience and vocational education are posited 
to have an impact on early termination (in hypothesis five and six), due to their correlation with obtaining a job (Benz, et al., 2000; Colley \& Jamison, 1998; Fabian, 2007; Fabian, et al., 1998; Wagner \& Blackorby, 1996). Hypothesis seven, that the presence of job benefits will have a significant impact on early termination, comes out of research showing that participation in the secondary job market can have adverse affects on youth obtaining jobs in the primary job market (Berger \& Piore, 1980), and that youth with disabilities are often placed into jobs in the secondary job market (Braddock, et al., 2005; Hasnain \& Balcazar, 2009; Waddoups \& Assane, 1997). In addition, the lack of job security in the secondary job market (Berger \& Piore, 1980) may contribute to early termination. Finally, because receiving SSI can have an adverse effect on obtaining a job, determining its impact on early termination is imperative. The TTW is included in the study because it is meant to alleviate this impact. Hypothesis eight posits that receiving SSI will have a significant impact on early termination, and hypothesis nine conjectures that utilization of the TTW will reduce the likelihood of early termination.

\section{Conclusion}

While very little research has been conducted on early termination, it remains an important concept in rehabilitation counseling literature. Focusing on early termination in internship job placement can help rehabilitation counselors and counselor educators identify which youth with disabilities are at risk for early termination from work. This enhanced understanding can aid service providers in targeting interventions in a job placement program, providing these youth with the opportunity to be as successful as possible in their employment. 


\section{Chapter Summary}

This chapter described school to work transition for youth with disabilities from a legislative and programmatic lens. It also included a description of best practices in transition as along with two transition approaches. Known barriers to transition were explored, all of which are variables that will be included in the current study. The chapter concluded with a discussion of the hypothesis presented in the paper, referencing literature that supported each hypothesis. 


\section{Chapter III}

\section{Method}

\section{Introduction}

This chapter discusses the methodology of this dissertation. This includes the research questions, hypotheses, participants, procedures, and instruments utilized, as well as how the data was analyzed. The research questions were as follows:

1. What reasons did youths with disabilities participating in a national multi-site vocational intervention program give for early termination from a job placement program for youth with disabilities?

2. What personal and programmatic variables (race, gender, type of disability, per capita income, prior work experience, previous vocational education, job benefits, and whether or not the individual is a Supplemental Security Income (SSI) recipient or is utilizing their Ticket to Work (TTW)) contributed to early termination from a job placement program for youth with disabilities?

Based on previous research, the hypotheses of this study were as follows:

Hypothesis 1: Race will have a significant impact on early termination (Blackorby \& Wagner, 1996; Entwisle, et al., 2000; Fabian, 2007; Gardecki, 2001).

Hypothesis 2: Gender will have a significant impact on early termination (Fabian, 2007; Gardecki, 2001).

Hypothesis 3: Type of disability will have a significant impact on early termination (Benz \& Halpern, 1993). 
Hypothesis 4: Per capita income will have a significant impact on early termination (Fabian, 2007).

Hypothesis 5: Prior work experience will have a significant impact on early termination (Colley \& Jamison, 1998; Fabian, 2007; Wagner, et al., 2005).

Hypothesis 6: Previous vocational education will have a significant impact on early termination (Colley \& Jamison, 1998; Karpur, et al., 2005; Wagner \& Blackorby, 1996).

Hypothesis 7: The presence of job benefits will have a significant impact on early termination (Hasnain \& Balcazar, 2009).

Hypothesis 8: Receiving supplemental security income will have a significant impact on early termination (Fabian, 2007).

Hypothesis 9: Utilizing the Ticket to Work will have a significant impact on early termination.

\section{Participants}

The participants in this study included students between the ages of 17 and 22 years old who lived in or near Atlanta, Chicago, Dallas, Los Angeles, Philadelphia, San Francisco, or Washington D. C. Students were referred to the program through their local schools, other community agencies, or families. They could also be self-referred. In order to participate in the program, they were required to provide documentation of their disability from a doctor or state vocational rehabilitation provider. Their school IEP is was considered an acceptable form of documentation. 
For this study, data was be utilized from 6,227 youth who entered the Bridges program between March 2004 and October 2010, 58.2\% of which were male and $41.8 \%$ of which were female. A majority of the participants were African American (61.4\%), followed by Hispanic participants (25.6\%), White participants (7.2\%), Asian participants $(2.7 \%)$, and those who reported "other" $(2.7 \%)$. The largest category of disability in the study was participants with learning disabilities, who made up $56.9 \%$ of the participants. Of the remaining participants, $10.7 \%$ had developmental disabilities, $5.6 \%$ had emotional/behavioral disabilities, $1.3 \%$ had sensory impairments, and $1.1 \%$ had physical disabilities. In terms of location, $17.6 \%$ of the participants were in Atlanta, $15.8 \%$ were in Chicago, 6.1\% were in Dallas, $23.8 \%$ were in Los Angeles, $13.5 \%$ were in Philadelphia, 13.3\% were in San Francisco, and 9.8\% were in Washington, DC.

Early termination was defined as being placed in a job but leaving the program prior to achieving any of the employment program benchmarks. Program benchmarks consisted of " 12 months of continuous employment, assuming specific additional job responsibility, commencement of post-secondary education or training, completion of vocationally related certification or training, moving into and sustaining an independent living situation, [and/or] moving from seasonal to permanent employment" (Marriott Foundation, 2008). In this study, $21.1 \%$ of the participants terminated early. However, only $16.3 \%$ of the total sample terminated early for negative reasons $(4.8 \%$ terminated early for positive reasons).

\section{Procedures}

Throughout the program, Bridges staff (employer representatives) collected data from the students. These data, identical at each Bridges site (Marriott Foundation, 2008), 
included information about how and when the data were to be collected from the student. Enrollment forms were completed as participants entered the program, and other forms (pre-employment, placement, and employment logs) ere updated regularly throughout the placement and job support process. In addition, follow-up data were collected at three months and twelve months after completion of the program (Marriott Foundation, 2008). Each individual employer representative inputted student data and then the data were combined at the Foundation's headquarters in Bethesda, Maryland, where administrative staff checked the consistency and reliability among program sites and staff at each site.

\section{Instrumentation}

The Bridges Forms and Files manual (Marriott Foundation, 2008) described the forms utilized for each step of the placement process: Intake, Pre-Employment, Placement/Employment, and Exit/Completion. For the purpose of this study, only the Intake, Placement/Employment, and Exit/Completion data were utilized. During the Intake process, an application form and an Enrollment Form/Participant Profile were created. The application form provided information about the participant's birth date, gender, school location, type of disability, and whether or not the participant was receiving SSI. The Enrollment Form/Participant Profile included information about whether or not the individual was utilizing the Ticket to Work. It also described previous work experience, such as whether or not the individual had been employed prior to enrolling in the program or had received vocational education. During the Placement/Employment portion of the program, the Placement Form was completed. This form provided information about the participant's job, describing their placement data and whether or not the job provides health insurance and vacation benefits. The Exit 
Form was filled out when the participant exited the program. It noted the participant's exit date, as well as describing why the participant terminated early, providing the following list of responses:

Transportation problems - Participant unable to reliably get to work due to a lack of transportation or an inability or unwillingness to use available transportation.

Moved away - Participant (or participant's family) relocated to an area or region making employment at current job unfeasible.

\section{Does not want to work - Participant specifically states a desire to no longer work.}

Financial aid interference - Participant's (or participant's family's) financial support/benefits from government subsidies are to be terminated or reduced if employment continues.

Interference with other services - Participant's employment interferes with the receipt of other services deemed important by the participant or his/her family.

Medical or health problems - Participant displays a health condition, which does not allow the participant to fully perform assigned duties, or where continued employment threatens to worsen a pre-existing health condition.

Participant not satisfied with job - Participant indicates that he/she is dissatisfied with some aspect of the placement.

Took better/other job - Participant resigned to take another position within the same company, or with another company that pays better, offers more hours, is more conveniently located, or is otherwise more desirable to the individual.

Other participant initiated - The participant initiated his/her separation for reasons other than those listed.

Other parent/guardian initiated - The family initiated the participant's separation for reasons other than those listed.

Program initiated - the Bridges program staff initiated the participant's separation. 
Slow business/business closed - Participant terminated or laid off due to business closing, budgeting cutbacks, or other economic reasons.

Participant worked too slowly - Participant was unable to maintain the necessary production requirements of the job.

Participant's work of low quality - Participant was unable to maintain necessary quality standards of the job.

Participant had poor appearance - Participant fails to maintain a physical appearance (facial hair, personal hygiene, clothing, etc.) acceptable to the employer.

Participant had poor social skills - Participant displays difficulty in effectively dealing with the social environment of the job.

Participant had poor attendance/punctuality - Participant displays repeated absences or late arrivals to work; may be accompanied by excuses of illness, transportation difficulties, etc.

Participant was insubordinate - Participant refuses to follow instructions or comply with supervisor's request.

Military enlistment - Participant has enlisted in the U.S. military program.

Other employer initiated - The employer initiated the participant's separation for reasons other than those listed (Marriott Foundation, 2008).

Because some of the reasons for early termination were positive or neutral, they did not indicate a potential problem. Therefore, only the negative reasons (in bold above) for early termination were included in the study. This list of negative versus positive reasons for early termination was developed using input from a researcher who has conducted multiple studies utilizing this data. Individuals who had a placement form in the database and who listed one or more of the bolded reasons were considered to have terminated 
early from the program for negative reasons. Of those who terminated early from the program, $16.3 \%$ did so for negative reasons.

\section{Data Analyses}

Preliminary data analyses demonstrated significant differences in early termination rates based on site. Using regression on multilevel data has been shown to violate the assumption of uncorrelated errors which is essential for regression (Luke, 2004). Additionally, research in the health sciences field explored the utilization of logistic regression versus multilevel modeling for nested data, determining that logistic regression can result in an increased likelihood of Type-I errors (Austin, Tu, \& Alter, 2003). For this reason, the data was analyzed using Hierarchical Linear Modeling (HLM). HLM is a statistical analysis used when data is nested (Raudenbush, Bryk, Cheong, \& Congdon, 2001). In this case, the nesting occurred at the program site level, although the analysis of variables occurred at the individual level. Using a two-level model (site and individual), the data analysis took into account the effect of program site and the individual participant's variables.

\section{Fully Unconditional Model}

The fully unconditional model was a means to test effects at the site level on early termination. While exploratory analyses using SPSS showed differences on site, this model was run through HLM, and used a logit transformation due to the binary nature of the dependent variable (Luke, 2004). The fully unconditional model was as follows:

$$
\begin{aligned}
& \text { Level1 }: \eta=\beta_{0 j}+r_{0} \\
& \text { Level2 }: \beta_{0 j}=\gamma_{00}+u_{0 j}
\end{aligned}
$$

This model included neither individual predictors (level-1 variables) nor site predictors (level-2 variables). The argument for utilizing Hierarchical Linear Modeling was 
demonstrated by showing that there are differences in early termination based on site using the intraclass correlation.

\section{Within-Site Model (Level 1)}

The within-site model showed the effect of individual level predictors (level-1) on early termination. At level-2, the model remained unconditional (similar to a null model). This allowed us to see how individual predictors (race, gender, type of disability, socioeconomic status, work experience, vocational education, vacation benefits, health benefits, SSI, and TTW) influenced the outcome variable of early termination. The level one model was as follows:

Level1 $: \pi_{0 j}($ EarlyTermination $)=\beta_{00}+\beta_{01}(\text { Race })_{j}+\beta_{02}(\text { Gender })_{j}+$

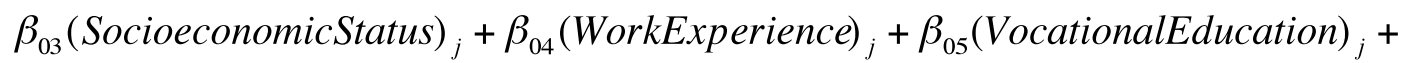

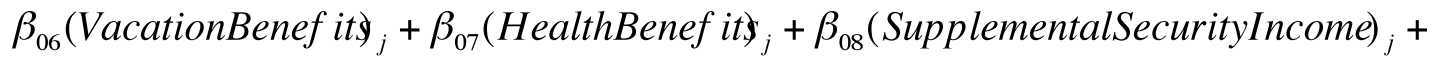
$\beta_{09}(\text { TicketToWork })_{j}+u_{0 j}$

These variables were discussed in depth in the between-site model.

\section{Between-Site Model (Level 2)}

The between-site model that was tested in this study included all of the predictor variables in the equation. Although similar to the within-site model, it also included the level-2 variable of site to control for the effect of site on the outcome variable. The model was as follows:

Level1 : $\pi_{0 j}($ EarlyTermination $)=\beta_{00}+\beta_{01}(\text { Race })_{j}+\beta_{02}(\text { Gender })_{j}+\beta_{03}\left(\right.$ TypeOf Disability ${ }_{j}+$

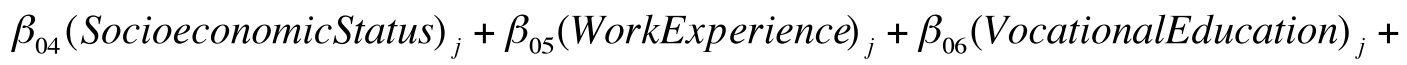
$\beta_{07}(\text { VacationBenef it })_{j}+\beta_{08}(\text { HealthBenef it })_{j}+\beta_{09}(\text { SupplementalSecurityIncome })_{j}+$ $\beta_{010}(\text { TicketToWork })_{j}+u_{0 j}$

$=\beta_{q j}+\sum_{q=1}^{Q} \beta_{q j} X_{q i j}+r_{i j}$

Level2: $\beta_{q j}=\gamma_{q 0}+\gamma_{q 1}($ site $)+u_{q j}$ 
This model contained the following variables:

Dependent Variable:

Early termination $\left(\pi_{0 j}\right)$, was defined as an individual who was placed in a job and had a placement date in the dataset but terminated early for one of the reasons listed in the Exit Form.

Level 1 Independent Variables:

Race $\left(\beta_{01}\right)$ : The independent variable of Race included: Asian $(2.7 \%)$, Black (61.4\%), Hispanic (25.6\%), White (7.2\%), Other (2.7\%).

Gender $\left(\beta_{02}\right)$ : The independent variable of gender included Male $(58.2 \%)$ and Female (41.8\%).

Type of Disability $\left(\beta_{03}\right)$ : The independent variable of Type of Disability included Autism Spectrum (0.5\%), Chronic Health Impairment (9.9\%), Cognitive Disability (13\%), Emotional/Behavioral Disorder (7\%), Hearing Impairment (1.2\%), Learning Disability (70.8\%), No Disability (1.4\%), Orthopedic Impairment (0.5\%), Speech/Language Impairment (0.7\%), Visual Impairment (0.5\%), and Other $(3.6 \%)$.

Socioeconomic Status $\left(\beta_{04}\right)$ : Socioeconomic status, defined as the average per capita income of the zip code of the school the youth attended, had a mean of $\$ 18,919$ per year with a minimum of $\$ 7,075$, a maximum of $\$ 91,147$, and a standard deviation of $\$ 9,797$. For the purpose of this study, this variable was centered and divided by 1,000 for ease of interpretability. 
Work Experience $\left(\beta_{05}\right)$ : The independent variable of work experience, defined as having been employed for six months prior to enrolling in the program, showed most of the participants to have no work experience (87.9\%). Only a small percentage of the sample was categorized as having work experience (12.1\%).

Vocational Education $\left(\beta_{06}\right)$ : The majority of the youth $(82.5 \%)$ had not received vocational education, while $17.5 \%$ had received some type of vocational training.

Vacation Benefits $\left(\beta_{07}\right)$ : The independent variable of receiving vacation benefits in a job placement showed that most of the youth were not receiving such benefits (94.0\%), although a small percentage were $(6.0 \%)$

Health Benefits $\left(\beta_{08}\right)$ : Most of the youth in the sample (90.4\%) were not receiving health benefits in their job placement, while (7.4\%) were.

Supplemental Security Income $\left(\beta_{09}\right)$ : Many of the individuals $(83.7 \%)$ were not receiving SSI, although $16.3 \%$ were.

Ticket to Work $\beta_{010}$ : For the independent variable of whether or not the individual was utilizing the TTW, $53.7 \%$ were not, $0.9 \%$ were, and $3.5 \%$ had applied to utilize the TTW.

Level 2 Independent Variable:

Site: The site (Atlanta, Chicago, Dallas, Los Angeles, Philadelphia, San Francisco, and Washington, D.C.) was included in the multilevel 
model to account for significant differences in early termination based on site.

The percentages of the sample representing each independent variable are shown in Table 3.1. 


\section{Table 3.1}

\begin{tabular}{|c|c|}
\hline Independent Variable & Percentage \\
\hline \multicolumn{2}{|l|}{ Race } \\
\hline Black & $61.4 \%$ \\
\hline Hispanic & $25.6 \%$ \\
\hline White & $7.2 \%$ \\
\hline Asian & $2.7 \%$ \\
\hline Other & $2.7 \%$ \\
\hline \multicolumn{2}{|l|}{ Gender } \\
\hline Male & $58.2 \%$ \\
\hline Female & $41.8 \%$ \\
\hline \multicolumn{2}{|l|}{ Type of Disability } \\
\hline Learning Disability & $70.8 \%$ \\
\hline Cognitive Disability & $13 \%$ \\
\hline Chronic Health Impairment & $9.9 \%$ \\
\hline Emotional/Behavioral Disorder & $7 \%$ \\
\hline Hearing Impairment & $1.2 \%$ \\
\hline Speech/Language Impairment & $0.7 \%$ \\
\hline Visual Impairment & $0.5 \%$ \\
\hline Autism Spectrum Disorder & $0.5 \%$ \\
\hline No Disability & $1.4 \%$ \\
\hline Other & $3.6 \%$ \\
\hline \multicolumn{2}{|l|}{ Work Experience } \\
\hline No & $87.9 \%$ \\
\hline Yes & $12.1 \%$ \\
\hline \multicolumn{2}{|l|}{ Vocational Education } \\
\hline No & $82.5 \%$ \\
\hline Yes & $17.5 \%$ \\
\hline \multicolumn{2}{|l|}{ Vacation Benefits } \\
\hline No & $94.0 \%$ \\
\hline Yes & $7.4 \%$ \\
\hline \multicolumn{2}{|l|}{ Health Benefits } \\
\hline No & $90.4 \%$ \\
\hline Yes & $16.3 \%$ \\
\hline \multicolumn{2}{|l|}{ Supplemental Security Income } \\
\hline No & $83.7 \%$ \\
\hline Yes & $16.3 \%$ \\
\hline \multicolumn{2}{|l|}{ Ticket to Work } \\
\hline No & $53.7 \%$ \\
\hline Yes & $0.9 \%$ \\
\hline Applied & $3.5 \%$ \\
\hline
\end{tabular}




\section{Chapter Summary}

This chapter presented the research questions and hypotheses of a study designed to explore the factors leading to early termination of a job placement program for youth with disabilities. It also included information about the participants and instrumentation

utilized in the study, such as Hierarchical Linear Modeling and the reasons it was chosen over other statistical approaches. 


\section{Chapter IV}

\section{Intro}

This chapter describes the methodology used for dealing with missing data, preliminary analyses, and the study's research questions. Each section is followed by the results, and the chapter concludes with a summary of key findings from the study.

\section{Missing data}

Due to the fact that the Bridges program has multiple sites where data is collected and entered, the dataset contains a large amount of missing data. In order to minimize the impact of this missing data while still retaining its integrity, the author conducted sequential regression imputation, an approach for imputation of missing at random data (Raghnuathan, Lepkowski, Van Hoewyk, \& Solenberger, 2001). Sequential regression was chosen because it has shown promise for the imputation of categorical variables. More common imputation techniques have been shown to be less useful for categorical variables (Enders, 2010). Due to time constraints, as well as difficulties with the program that conducts sequential regression imputation, imputation was not conducted. However, Hierarchical Linear Modeling (HLM) includes methods to include or exclude missing data (Raudenbush, et al., 2001). To retain the maximum amount of data possible when making the MDM (HLM Data file) file in the HLM-6 program, missing data was deleted when running analyses (as opposed to the option of deleting case-wise when making the data file). The missing data information for each independent variable is included in Table 4.1. 


\section{Table 4.1}

Variable

Asian

Number Analyzed Number Missing

Per Capita Income

6193

34

Emotional or Behavioral Disorder

6112

115

Gender

6001

226

6227

0

\section{Preliminary Analyses}

Frequencies. A frequency analysis was conducted to develop a stronger understanding of the data. The frequencies of each variable are shown in Table 4.2. 


\section{Table 4.2}

\section{Independent Variable}

Race

Black

Hispanic

White

Asian

American Indian

Other

Gender

Male

Female

Type of Disability

Learning Disability

Cognitive Disability

Chronic Health Impairment

Emotional/Behavioral Disorder

Hearing Impairment

Speech/Language Impairment

Visual Impairment

Autism Spectrum Disorder

No Disability

Other

Work Experience

No

Yes

Vocational Education

No

Yes

Vacation Benefits

No

Yes

Health Benefits

No

Yes

Supplemental Security Income

No

Yes

Ticket to Work

No

Yes

Applied
Percentage

$63 \%$

$22.40 \%$

$8.40 \%$

$2.90 \%$

$0.30 \%$

$2.50 \%$

$58.70 \%$

$41.30 \%$

$70.80 \%$

$13 \%$

$9.90 \%$

$7 \%$

$1.20 \%$

$0.70 \%$

$0.50 \%$

$0.50 \%$

$1.40 \%$

$2.60 \%$

$87.90 \%$

$12.10 \%$

$82.50 \%$

$17.50 \%$

$94.00 \%$

$7.40 \%$

$90.40 \%$

$16.30 \%$

$83.70 \%$

$16.30 \%$

$53.70 \%$

$0.90 \%$

$3.50 \%$ 
Correlation analyses. In order to gain a rudimentary understanding of the relationship between each independent variable and the dependent variable prior to the logistic regression and Hierarchical Linear Modeling analysis, bivariate correlations were run. The correlational analyses resulted in four significant results. Having previous vocational education experience was positively correlated with early termination and was significant at the 0.05 level. Also significant at the 0.05 level was a negative correlation between having a learning disability and terminating early. At the 0.01 level, individuals with emotional or behavioral disabilities were more likely to terminate early, and Asian individuals with disabilities were less likely to terminate work early. These correlations are shown in Table 4.3 and 4.4. 


\section{Table 4.3}

\section{Correlations}

Early Termination

Gender

6 Months Previous Employment

Vocational Education Experience

Health Benefits

Vacation Benefits

Receiving SSI

White

African American

Hispanic

Asian

Race Other

Ticket to Work - Yes

Ticket to Work - No
Pearson Correlation Sig. (2-tailed)

$\mathrm{N}$

Pearson Correlation

Sig. (2-tailed) $\mathrm{N}$

Pearson Correlation

Sig. (2-tailed)

$\mathrm{N}$

Pearson Correlation

Sig. (2-tailed)

$\mathrm{N}$

Pearson Correlation

Sig. (2-tailed)

$\mathrm{N}$

Pearson Correlation

Sig. (2-tailed)

$\mathrm{N}$

Pearson Correlation

Sig. (2-tailed)

$\mathrm{N}$

Pearson Correlation

Sig. (2-tailed)

N

Pearson Correlation

Sig. (2-tailed)

$\mathrm{N}$

Pearson Correlation

Sig. (2-tailed)

$\mathrm{N}$

Pearson Correlation

Sig. (2-tailed)

N

Pearson Correlation

Sig. (2-tailed)

$\mathrm{N}$

Pearson Correlation

Sig. (2-tailed)

$\mathrm{N}$

Pearson Correlation

Sig. (2-tailed)

$\mathrm{N}$
Early Termination

1

6227

0.009

0.464

6227

$-0.014$

0.314

5365

0.027

6227

$-0.01$

0.502

4800

$-0.011$

0.453

4800

0.011

0.407

5939

$-0.01$

0.436

6193

0.014

0.287

6193

0.001

0.932

6193

0.001

6193

0.016

0.204

6193

$-0.008$

0.613

3614

0.022

0.193

3614 


\section{Table 4.4}

\section{Correlations (Continued)}

Ticket to Work - Applied

Pearson Correlation $\quad-0.02$

Sig. (2-tailed) $\quad 0.236$

Per Capita Income (Centered)

$\mathrm{N}$

3614

Pearson Correlation $\quad 0.02$

Sig. (2-tailed) $\quad 0.112$

$\mathrm{N}$

6112

Developmental Disability

Pearson Correlation

0.021

Sig. (2-tailed)

0.102

$\mathrm{N}$

6001

Emotional or Behavioral Disability

Pearson Correlation

$.035^{* *}$

Sig. (2-tailed) $\quad 0.007$

Learning Disability

$\mathrm{N}$

Pearson Correlation - $-.031 *$

$\begin{array}{lr}\text { Sig. (2-tailed) } & 0.015 \\ \mathrm{~N} & 6001\end{array}$

Sensory Disability

Pearson Correlation

$-0.005$

Sig. (2-tailed)

0.676

$\mathrm{N}$

6001

Physical Disability

Pearson Correlation

$-0.019$

Sig. (2-tailed)

0.136

$\mathrm{N}$

6001

Other Disability

Pearson Correlation

$-0.005$

Sig. (2-tailed)

0.724

$\mathrm{N}$

6001

*. Correlation is significant at the 0.05 level (2-tailed).

**. Correlation is significant at the 0.01 level (2-tailed).

\section{Research Question I}

Research question one, identifying the reasons that youth with disabilities participating in a national multi-site vocational intervention program gave for early termination, was approached using frequency analysis. The reasons for early termination and their frequencies are included in Table 4.5. 


\section{Table 4.5}

\section{Reasons for Early Termination}

Program initiated

Does not want to work

Returned to school

Moved away

Interpersonal conflict with supervisor or coworker

Enrolled in another program

Medical or health problems

Not satisfied with job

Transportation problems

Participant abandoned job and quit

Participant's work of low quality

Fired for violating employer policy

Financial Aid Interference

Inappropriate behavior with Employment Representative

Quit Job in Lieu of Termination

Other

$\begin{array}{ll}\begin{array}{l}\text { Frequency } \\ \text { Yes }\end{array} & \begin{array}{l}\text { Frequency } \\ \text { No }\end{array} \\ 822(13.2 \%) & 526(8.4 \%) \\ 650(10.4 \%) & 525(8.4 \%) \\ 579(9.3 \%) & 538(8.6 \%) \\ 298(4.8 \%) & 542(8.7 \%) \\ 193(3.1 \%) & 575(9.2 \%) \\ 160(2.6 \%) & 566(9.1 \%) \\ 118(1.9 \%) & 570(9.2 \%) \\ 68(1.1) \% & 574(9.2 \%) \\ 37(0.6 \%) & 578(9.3 \%) \\ 36(0.6 \%) & 543(8.7 \%) \\ 17(0.3 \%) & 562(9.0 \%) \\ 21(0.3 \%) & 558(9.0 \%) \\ 11(0.2 \%) & 576(9.3 \%) \\ 11(0.2 \%) & 568(9.1 \%) \\ 5(0.1 \%) & 574(9.2 \%) \\ 983(15.8 \%) & 483(7.8 \%)\end{array}$

The two positive reasons cited for early termination included returned to school and enrolled in another program. Additionally, there were neutral reasons for early termination, the three most prevalent of which included does not want to work moved away, and medical or health problems. The three most common negative reasons for early termination included program initiated, interpersonal conflict with supervisor or coworker, and transportation problems.

This descriptive data suggests a number of areas for the Bridges program to explore, to ensure lower early termination rates in program participants. For example, because a majority of those who terminated early did so due to non-compliance with Bridges procedures, it is possible that procedures for the program would benefit from slight changes. Such changes may allow a larger number of participants to succeed. Additionally, the high rate of termination due to interpersonal conflicts may indicate a 
potential need for interpersonal skills training for individuals with disabilities. Finally, the high rate of termination due to transportation problems suggests that the Bridges program would benefit from an intervention that could assist youth with transportation problems. These ideas will be discussed further in Chapter 5.

\section{Research question II}

Research question two focused on what personal and programmatic variables (e.g., race, gender, type of disability, per capita income, prior work experience, previous vocational education, job benefits, and whether or not the individual is an SSI recipient or is utilizing their TTW) contributed to terminating early from a job placement program for youth with disabilities. To answer this question, a stepwise logistic regression was run, followed by HLM analysis.

\section{Stepwise Logistic Regression}

To determine which variables belonged in the HLM analysis, a backward stepwise logistic regression was run. This allowed for the development of a more parsimonious model prior to conducting the HLM analysis. Eighteen variables were initially entered into the regression equation: African American, Hispanic, Asian, Other Race, Not using Ticket to Work, Applied for Ticket to Work, Per Capita Income centered and reduced to thousands, Male, Six Months Previous Employment, Previous Vocational Education, Receiving Health Benefits, Receiving Vacation Benefits, Receiving Supplemental Security Income, Developmental Disability, Emotional or Behavioral Disability, Sensory Disability, Physical Disability, and Other Disability. At step 15 the model was complete, demonstrating that whether or not the individual was Asian, their per capita income, whether or not the individual was male, and whether or 
not the individual had an emotional or behavioral disturbance all had a significant impact on early termination. The final results (step 15) of this backward stepwise logistic regression are included in Table 4.6. 
Table 4.6

Model if Term Removed

\begin{tabular}{|c|c|c|c|c|c|}
\hline \multicolumn{2}{|c|}{ Variable } & $\begin{array}{l}\text { Model Log } \\
\text { Likelihood }\end{array}$ & $\begin{array}{c}\text { Change in -2 Log } \\
\text { Likelihood }\end{array}$ & $\mathrm{df}$ & $\begin{array}{l}\text { Sig. of the } \\
\text { Change }\end{array}$ \\
\hline \multirow{4}{*}{$\begin{array}{l}\text { Step } \\
15\end{array}$} & Asian & -1109.686 & 8.955 & 1 & .003 \\
\hline & Per Capita Income & -1108.747 & 7.078 & 1 & .008 \\
\hline & Gender & -1107.044 & 3.672 & 1 & .055 \\
\hline & Emotional or Behavioral disability & -1110.722 & 11.026 & 1 & .001 \\
\hline
\end{tabular}

Utilizing these results, the variables Asian, Per Capita Income, Gender, and Emotional or Behavioral Disability were included in the subsequent HLM.

\section{Hierarchical Linear Modeling}

In order to conduct HLM, the fully unconditional model was run to determine variance between sites and the need for hierarchical analysis. This was followed by running the prediction model, which includes all of the variables determined to be significant through the logistic regression, while controlling for site.

Fully-Unconditional Model. The HLM analysis was approached initially by conducting the fully-unconditional model:

$$
\begin{aligned}
& \text { Levell }: \eta=\beta_{0 j}+r_{00} \\
& \text { Level } 2: \beta_{0 j}=\gamma_{00}+u_{0 j}
\end{aligned}
$$

As discussed in Chapter Three, this model includes no level-1 or level-2 predictors, allowing for a determination of whether or not it is necessary to conduct hierarchical analysis. The fully unconditional model resulted in a Tau value of 0.53669 , which allowed for a determination of intraclass correlation utilizing the following equation: 


$$
\begin{aligned}
I C C & =\frac{\tau}{\left(\tau+\frac{\pi^{2}}{3}\right)} \\
I C C & =\frac{.053669}{(.053669+3.289868134)} \\
I C C & =0.01605
\end{aligned}
$$

Calculating the intraclass correlation, which is the percent of variance between sites, yielded a value of 0.01605 . This demonstrated the need to run the HLM (Raudenbush, et al., 2001).

Prediction Model. In order to determine the impact of the variables included in the analysis (Asian, Per Capita Income, Emotional or Behavioral Disability, and Gender), and ensure that these differences were not due to differences based on site, the prediction model was run. The model included the following equation:

Level $: \pi_{0 j}($ EarlyTermination $)=\beta_{00}+\beta_{01}(\text { Asian })_{j}+\beta_{02}(\text { Male })_{j}+$

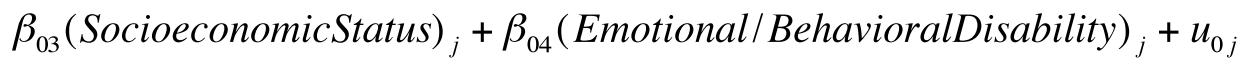
$=\beta_{q j}+\sum_{q=1}^{Q} \beta_{q j} X_{q i j}+r_{i j}$ Level2: $\beta_{q j}=\gamma_{q 0}+\gamma_{q 1}($ site $)+u_{q j}$ It is important to note that each independent variable was added to the model uncentered, because there was no interest in interactions between independent variables. Due to the listwise deletion of variables, all 6,227 participants were included in the analysis, however there were missing datapoints as delineated above in table 4.1. This model resulted in one significant variable, demonstrating that individuals with disabilities who are Asian are $63 \%$ less likely to terminate work early than White individuals with disabilities when controlling for site. However, while not significant at the 0.05 level, having an emotional or behavioral disability resulted in a 19\% higher chance of 
terminating work early when controlling for site. The results of the prediction model are in Table 4.7. 


\section{Table 4.7}

Variable
Intercept
Asian
Per Capita Income
Emotional/Behavioral
Disability
Gender

\section{Coefficient}

$-1.602487$

$-0.974535$

0.006138

0.307063

$-0.051588$

\section{Confidence Interval}

$(0.181,0.224)$

$(0.213,0.669)$

$(0.999,1.013)$

$(1.062,1.740)$

$(0.824,1.093)$
Odds Ratio

0.201395

0.377368

1.006157

1.359427

0.949720
P-Value

0.000

0.000

0.503

0.091

0.430

\section{Summary of Key Findings}

The key findings from this study are that individuals with disabilities are more likely to terminate early due to non-compliance with program procedures, transportation problems, or interpersonal conflicts with their supervisor or coworker. Additionally, Asian youth with disabilities are $63 \%$ less likely to terminate early from a job or internship placement. This is consistent with previous research on job placement, which has shown Asian youth to have better chances of obtaining work (Blackorby \& Wagner, 1996; Entwisle et al., 2000; Fabian, 2007; Hasnain \& Balcazar, 2009; Wagner et al., 2005). Additionally, the finding that youth with emotional/behavioral disabilities are more likely to terminate early from work is consistent with previous research on early termination (Benz \& Halpern, 1993).

\section{Chapter Summary}

This chapter focused on the various methods utilized to analyze the dataset. Beginning with descriptions of the preliminary analyses (frequency and correlation analyses), it went on to present the results of the two research questions, along with the results from the preliminary backward stepwise regression. The chapter concluded with a 
discussion of the HLM (both the fully unconditional model and the predication model) and concluded with a summary of key findings. 


\section{Chapter V}

\section{Introduction}

This chapter begins by linking the findings of the study to the initial research questions and existing research. It is followed by a discussion of the limitations and implications of the study. The chapter concludes with a section proposing future research on the topic that would be beneficial to the field.

\section{Linking Findings to Research Questions}

This dissertation explores how personal and programmatic variables relate to early termination of an internship program for youth with disabilities. The first research question explores the reasons for early termination, while the second question examines the relationship between these variables using HLM.

\section{Research Question 1}

The first research question, "what reasons did youth with disabilities participating in a national multi-site vocational intervention program give for early termination from the program?" showed that the three main negative reasons for early termination included program initiated termination, termination due to interpersonal conflict with a supervisor or coworker, and transportation problems.

The high rates of program-initiated termination are due to the current procedures in place. A cursory glace at the qualitative data included in the dataset indicated that in a number of cases this meant that the student had poor attendance or punctuality. This may indicate that there may be a need for the Bridges program to alter their requirements and procedures to alleviate the difficulties involved in remaining in the internship program. 
The youth in the program are young, between 17 and 22 years old. Perhaps allowing them a larger number of mistakes before terminating them from the program could assist them in more successfully making the transition from school to work.

Understanding that a number of the youth with disabilities terminated work early due to an interpersonal conflict with their supervisor or coworker can help the Bridges program take steps to alleviate the potential for these problems. Often, the data for these youth in the dataset included qualitative data indicating that the youths had poor social skills. This could indicate that providing Bridges program participants with interpersonal skills training could help to minimize the potential for interpersonal conflicts in the workplace. Another possible option is providing mediation training for the employment representatives who provide services to youth with disabilities. With this training, employment representatives can help mediate conversations between the youth and the supervisor or coworker with whom they are in conflict.

Finally, the fact that youth are experiencing transportation problems, which cause them to terminate early from the program, is one that may be easily rectified. In a few of these cases, qualitative data indicated that the youth also had poor attendance and punctuality, likely due to the transportation barriers they were encountering. Perhaps the program could provide transportation stipends to assist the youth in getting to work, particularly while the youth is beginning the program. For example, during the first few months, financial assistance for transportation could be provided in order to assist the youth in getting themselves situated in terms of transportation, and to potentially allow for them to save money for transportation costs in the future. In addition, if a program participant anticipates having transportation problems, perhaps he or she could be placed 
in a job in close proximity to their school or home, minimizing the potential for transportation to be an issue.

Taking steps to reduce the impact of these main reasons for early termination may allow more Bridges participants to be successful in the internship and job process. Recognizing the possible limitations of the program, and implementing methods to circumvent the impact of these difficulties, may go a long way in increasing participant success in the internship process.

\section{Research Question 2}

The second research question for this dissertation was "what personal and programmatic variables (race, gender, per capita income, prior work experience, previous vocational education, job benefits, and whether or not the individual is receiving SSI or utilizing their TTW) contributed to terminating early from a job placement program for youth with disabilities?" This research question was broken down into nine different hypotheses based on previous research. The results of each of the hypotheses are discussed in the following section.

Hypothesis One. Hypothesis one, that race will have a significant impact on early termination, was found to be true. This was based on a number of studies (e.g. Blackorby \& Wagner, 1996; Entwisle, et al., 2000; Fabian, 2007; Gardecki, 2001), all of which found a relationship between race and job placement. Similar to these studies, this research found that Asian students with disabilities were $63 \%$ less likely to terminate early from work than White individuals with disabilities. The relative success of Asian youth with disabilities has been demonstrated in other studies with regards to obtaining employment. These studies also found that White youth with disabilities were more 
likely to obtain employment (Blackorby \& Wagner, 1996; Entwisle et al., 2000; Fabian, 2007; Hasnain \& Balcazar, 2009; Wagner et al., 2005). However, the studies examined the relationship between race and obtaining employment, whereas this study focused on the relationship between race and early termination from work.

It is important to note that although Asian American youth were less likely to terminate early, and there were not significant results of early termination related to other minority youth, that the interpretations not jump to the "model minority" mindset. When interpreting these results, the impact of structural barriers that continue to exist for minority youth (e.g. D'Amico, 1984), as well as the potential for implicit bias on the part of the service provider when working with and placing the student must remain in the forefront of the mind.

Hypothesis Two. Hypothesis two, that gender will have a significant impact on early termination was not supported. This is contrary to previous research which indicated that gender has a significant impact on obtaining employment (Fabian, 2007; Gardecki, 2001). This may be due to the fact that both of these studies utilized data collected approximately a decade prior to the data used in this study. Additionally, both of these studies had an outcome variable that was being placed in a job, therefore did not study early termination as this study did..

Hypothesis Three. Hypothesis three, that type of disability will have a significant impact on early termination, was marginally supported by the analyses. While not statistically significant based on the p-value, data analysis demonstrated that individuals with emotional or behavioral disabilities were $35 \%$ more likely to terminate early from 
the internship program. This is consistent with what little research has previously been conducted on early termination (Benz \& Halpern, 1993).

Hypothesis Four. Hypothesis four, that per capita income will have a significant impact on early termination, was not supported in the analysis. The impact of per capita income on early termination had not previously been studied, but was included in the analysis as youth with disabilities tend to earn lower wages than their counterparts without disabilities (Fabian, 2007).

Hypothesis Five. Hypothesis five, that prior work experience will have a significant impact on early termination, was not supported. This is interesting, as research on prior work experience has shown that prior work experience has a significant impact on posthigh school employment (Benz, et al., 2000; Colley \& Jamison, 1998; Fabian, 2007;

Fabian, et al., 1998). However, none of these studies look at youth who obtain employment but leave it prior to meeting employment benchmarks, instead looking solely at whether or not the youth are employed.

Hypothesis Six. Hypothesis six, that previous vocational education will have a significant impact on early termination, was not supported by the analysis. This is inconsistent with previous research that showed that vocational education let to positive post-school outcomes (Colley \& Jamison, 1998; Wagner \& Blackorby, 1996), however these studies looked solely at employment, and not early termination.

Hypothesis Seven. Hypothesis seven, that the presence of job benefits will have a significant impact on early termination, was not supported. Neither health benefits nor vacation benefits, the two variables that indicated the presence of benefits, were found to be significant in the model. These variables were included based on understanding of the 
first and secondary labor market, and that youth with disabilities are more likely to be placed in the secondary labor market (Waddoups \& Assane, 1997). While the impact of these variables on had not previously been studied, the lack of significance in this study does not mean the impact of these variables should no longer be included in analyses of work or early termination for youth with disabilities, as limitations within this study may have led to the non-significance on these variables.

Hypothesis Eight. Hypothesis eight, that receiving Supplemental Security Income will have a significant impact on early termination, was not supported by the analysis. This is contrary to Fabian's (2007) study, which found that youth receiving Supplemental Security Income were less likely to find work, however the differences in outcome variables and datasets likely contribute to these differences.

Hypothesis nine. Hypothesis nine, that utilizing the Ticket to Work will have a significant impact on early termination, was not found to be significant. This was the only hypothesis not supported by previous research.

While there is an obvious interest in the variables that demonstrated a significant impact on early termination, those that did not demonstrate significance continue to be important. Results of non-significance may be due to the limitations of the study.

\section{Limitations}

While the results from this study provide insight into what factors influence high school students with disabilities to terminate their involvement in a job placement program, it is important to be aware of the limitations of this study. In terms of the study sample, the participants in this dataset are disproportionately youth with learning disabilities and most are African American or Hispanic. This poses a limitation to the 
study because it is not using a representative sample for the analyses, limiting its generalizability. The lack of variability in race and type of disability may also limit any interpretation of differences based on these variables. In addition, the Bridges participants may not be representative of all youth with disabilities because they elected join to or were referred to the Bridges program, suggesting that they were already motivated to work. These participants were already in their final years of high school, demonstrating a level of persistence and support that may contribute to a higher success rate than other youth with disabilities. Another consideration is that, in large sample sizes, the probability of finding statistical significance is increased. This requires more focus on the substantive rather than the statistical differences.

With regard to the data used in the study, numerous service providers collect the data for this study at multiple sites across the United States, influencing the consistency of the data. While the Bridges administrative staff strives to ensure consistency in data collection, it is impossible for them to constantly monitor data collection at all sites. The Bridges database also includes large amounts of missing data. This missing data did not appear to have any sort of pattern, but it might not be missing at random. This introduces potential biases into the analysis, which may have impacted significance of the variables included or omitted from the model. In addition, variables such as school setting (segregated special education, special education in regular school, regular classroom with resource room, regular classroom with in class services, and placement without special support services) that could be beneficial to include in the study, cannot be ascertained from the limited data. In addition, the current instrument used for the study allows for multiple reasons for early termination to be specified. This can make it more difficult to 
study reasons for early termination. These reasons for early termination are very important, as they are a transition outcome that has not often been studied, and can give researchers and service providers more insight into barriers in transition for youth with disabilities.

It is important to note that the dependent variable is identified through self-report. This means there is a potential for response bias in the reasons given for early termination. Youth are asked to identify the reasons for early termination by the employer representative with whom they have been working. The youth may not be willing to respond truthfully, preferring to reply in a socially desirable manner. There is also the possibility of missing data, because it is difficult for an employer representative to obtain the reason for termination if the youth does not respond to communication attempts. A reason coded in the database as "no response to contact" may have underlying reasons for early termination not demonstrated in the dataset. In addition, multiple reasons for early termination can be identified in the datasets. In several cases, both positive and negative reasons for termination were reported, making it impossible to analyze the data in such a way that the outcomes could be dichotomized.

Site-level variables, which were controlled for but not included in the study, may pose an additional limitation. For example, factors such as the funding sources for sites, the relative unemployment rates of the areas in which the sites are located, and the case loads of employer representatives at each site may all have an impact on early termination. However, their effects were not addressed in this study.

Finally, the non-experimental nature of this research provides another limitation to the study's generalizability. Because the youth with disabilities were not placed into 
treatment and control groups, there is no control group available for comparison.

Additionally, this study utilized a data driven approach, using results from the Stepwise Logistic Regression to drive the model specified for the Hierarchical Linear Modeling analysis, further limiting the generalizability of this research. Both of these limitations increase the difficulty of drawing conclusions of causality from the research.

\section{Implications}

Despite its limitations, the results of the study still demonstrate the importance of the research. It is one of very few studies that look at the factors related to early termination, so the results are novel to the field. Additionally, it has implications for many stakeholders in the transition process, including transition programs (specifically the Bridges program), schools, policymakers, and youth with disabilities and their families.

For transition programs such as the Bridges program, data showing that youth with emotional or behavioral disabilities have extra difficulties in transition and are more likely to terminate early than individuals with any other disability can help programs take steps to ensure the success of high-risk youth. Paying special attention to these youth and providing them with extra supports for success could ameliorate the transition barriers related to their type of disability. The Bridges program may also be able to better serve youth with disabilities if procedures are changed to allow more opportunities for success. Additional leeway in program procedures would minimize termination due to noncompliance.

The Bridges program could also assist youth with disabilities in identifying options for transportation, supporting youth with any transportation problems. Such 
actions would help reduce early termination due to transportation issues. Providing youth with disabilities with interpersonal skills training is another area for program expansion, lessening the likelihood that a youth with a disability will terminate early due to interpersonal conflicts with employers or supervisors. Offering mediation training to employer representatives who work with both youth with disabilities and their employers positions the representatives to help mediate potential workplace problems.

While transition programs such as the Bridges program may benefit from providing interpersonal skills training to youth with disabilities, such training could also be provided in schools before participants enter a transition program. With this training, youth would enter the program better prepared to build and maintain relationships with their supervisors and coworkers. Early intervention through the school system would allow youth to focus solely on employment while in transition.

For policy makers, the major implication of this study is the need to create policy focused on transportation assistance for youth with disabilities during the transition process. While there are current policies to assist youth with disabilities with transportation problems through the TTWWIIA (Congress, 1999), these policies only cover youth who are eligible for the other benefits in the act. That means that youth who are not 18 or over and who do not receive SSI cannot utilize these policies to assist with transportation. Recognizing the impact of transportation problems on early termination can aid policy makers in developing funding programs for youth with disabilities who need transportation assistance during transition. Those individuals who serve on city transportation boards could also implement policies to assist youth within individual cities. 
Youth with disabilities and their families, as well as rehabilitation counselors, school counselors, transition specialists, and other stakeholders in the transition process, have the ability to utilize these results to advocate for youth with disabilities. These stakeholders and advocates can campaign for special transition supports for youth with emotional or behavioral disabilities, interpersonal skills training prior to and during transition, and assistance for youth with disabilities experiencing transportation difficulties. Because of the important implications that stem from this research, implications that point to the potential for decreased levels of early termination from transition programs, it is important that stakeholders and policymakers take note of these implications to institute change.

\section{Future Research}

As has been demonstrated, the need for research on early termination is extensive. Not only has very little research been conducted on individuals who terminate early and fall through the cracks of the transition process, this dissertation has been largely inconclusive due to the limitations of the study. However, the study and its limitations indicate many areas for future research that would be beneficial to the field by providing a better understanding of early termination and transition programs.

A qualitative study interviewing the stakeholders in the transition process would be a considerable contribution to the exploration of early termination. Speaking with individuals with disabilities, their families, and their employer representatives or transition specialists could give researchers a more comprehensive view of the transition process and early termination factors. Utilizing individual interviews and focus groups 
may help researchers come to a more comprehensive understanding of what causes early termination from a transition program.

Additionally, the dataset developed by the Bridges program includes many important variables that can be utilized for a study on early termination. However, to ensure the success of future studies, large-scale changes need to be made to the database. If the program overhauled its data input process, the early termination factors could be better researched. Luckily, there are other databases that provide transition data for youth with disabilities. The National Longitudinal Transition Study $-2($ NLTS -2$)$ could be utilized to compare youth who terminate work early with those who do not, providing more information about early termination and its contributing factors. Because the NLTS -2 uses a sample that is nationally representative (National Center for Special Education Research, n.d.), its data would alleviate some of generalizability limitations that exist in the Bridges program dataset. Additionally, the NLTS -2 dataset includes different variables and assessments that would allow for a broader conceptualization of early termination.

Research on early termination continues to be important and necessary. This aspect of transition can help us better serve youth with disabilities who are falling through the cracks during the transition process. Although it has been under-studied in the past, it is essential that early termination remain a topic of research for those who are interested in transition.

\section{Conclusion}

This dissertation examines an under-studied population in transition: those who obtain a job but are unable to retain it and terminate work early. In order to provide 
comprehensive transition services, it is essential that researchers and practitioners understand what variables relate to a lack of success for these youth. This study identifies reasons given for early termination from an internship program for youth with disabilities, as well as personal factors that contribute to early termination. This dissertation concludes with implications for policy makers, transition programs, schools, and other stakeholders in the transition process, along with ideas for future research. 


\section{References}

Administration, S. S. (2011a). Benefits For People With Disabilities Retrieved January 10, 2012, from http://www.ssa.gov/disability/

Administration, S. S. (2011b). Monthly Statistical Snapshot, November 2011 Retrieved January 10, 2012, 2012, from http://www.ssa.gov/policy/docs/quickfacts/stat snapshot/

Administration, S. S. (2011c). Ticket to Work Program Basics. In S. S. Administration (Ed.), (pp. 1-2). Washington, DC.

Administration, S. S. (2011d). Understanding Supplemental Security Income: SSI Eligibility Requirements Retrieved 2-14-12, 2012, from http://www.ssa.gov/ssi/text-eligibility-ussi.htm

Agran, M., \& Wehmeyer, M. L. (2000). Promoting transition goals and selfdetermination through student self-directed learning: The Self-Determined Learning Model of Instruction. Education and Training in Mental Retardation and Developmental Disabilities, 35(4), 351-364.

Austin, P. C., Tu, J. V., \& Alter, D. A. (2003). Comparing heirarchical modeling with traditional logistic regression analysis among patients hospitalized with acute myocardial infarction: Should we be analyzing cardiovascular outcomes differently? American Heart Journal, 145(1), 27-35.

Bandura, A. (1994). Self-efficacy (Vol. 4). New York: Academic Press.

Becker, D. R., Drake, R. E., Bond, G. R., Xie, H., Dain, B. J., \& Harrison, K. (1998). Job terminations among persons with severe mental illness participating in supported employment. Community Mental Health Journal, 34(1), 71-82. 
Benz, M. R., \& Halpern, A. S. (1993). Voctional and transition services needed and received by students with disablities during their last year of high school. Career Development for Exceptional Individuals, 16(2), 197-211.

Benz, M. R., Lindstrom, L., \& Yovanoff, P. (2000). Improving graduation and employment outcomes of students with disabilities: Predictive factors and student perspectives. Exceptional Children 66(4), 509-529.

Berger, S., \& Piore, M. (1980). Dualism and discontinuity in industrial society. Cambridge, UK: Cambridge University Press.

Berry, H. G. (2000). The Supplemental Security Income program and employment for young adults with disabilities: An analysis of the National Health Interview Survey on Disability. Focus on Autism and Other Developmental Disabilities, 15(3), 176-181.

Blackorby, J., \& Wagner, M. (1996). Longitudinal post school outcomes of youth with disabilities: Findings from the National Longitudinal Transition Study. Exceptional Children, 62(399-413).

Boeltzig, H., Timmons, J. C., \& Butterworth, J. (2008). Entering work: Employment outcomes of people with developmental disabilities. International Journal of Rehabilitation Research, 31(3), 217-223.

Braddock, D., Hemp, R., \& Rizzolo, M. C. (2005). The state of the states in developmental disabilities. Boulder, CO: Coleman Institute for Cognitive Disabilities.

Bronfenbrenner, U. (1989). Ecological Systems Theory. Annals of Child Development, $6,187-249$. 
Bureau, U. S. C. (2009). 15th Anniversary of Americans with Disabilities Act: July 26, 2005. Facts for Features Retrieved October 14, 2009, from http://www.census.gov/PressRelease/www/releases/archives/facts for features special editions/00499 $\underline{8 . h t m l}$

Carter, E. W., Austin, D., \& Trainor, A. A. (2011). Predictors of postschool employment outcomes for young adults with severe disabilities. Journal of Disability Policy Studies, 22. doi: 10.1177/1044207311414680

Carter, E. W., \& Wehby, J. H. (2003). Job performance of transition-age youth with emotional and behavioral disorders. Exceptional Children, 69(4), 449-465.

Certo, N. J., Luecking, R. G., Brown, L., Courey, S., \& Belanger, D. (2008). Seamless transition and long-term support for individuals with severe intellectual disabilities. Research and Practice for Persons with Severe Disabilities, 33(3), 85-95.

Certo, N. J., Mautz, D., Pumpian, I., Sax, C. L., Smalley, K., Wade, H. A., et al. (2003). Review and discussion of a model for seamless transition to adulthood. Education and Training in Developmental Disabilities, 38(1), 2-17.

Certo, N. J., \& Pumpian, I. (1997). Focusing on the point of integration: A service integration model. Education \& Treatment of Children, 20(1), 68-85.

Colley, D. A., \& Jamison, D. (1998). Post school results for youth with disabilities: Key indicators and policy implications. Career Development for Exceptional Individuals, 21(2), 145-160. 
Ticket to Work and Work Incentives Improvement Act of 1999, Congress 1859-1951 (1999).

D'Amico, R. (1984). Does employment during high school impair academic progress? Sociology of Education, 57, 152-164.

ed.gov. (2000). History: Twenty-five years of progress in educating children with disabilities through IDEA Retrieved November 17, 2011, 2011, from http://www2.ed.gov/policy/speced/leg/idea/history.html

Enders, C. K. (2010). Applied missing data analysis (Methodology in the Social Sciences). New York: The Guilford Press.

Entwisle, D. R., Alexander, K. L., \& Olson, L. S. (2000). Early work histories of urban youth. American Sociological Review, 65, 279-297.

Fabian, E. S. (2007). Urban youth with disabilities: Factors affecting transition employment Rehabilitation Counseling Bulletin, 50(3), 130-138.

Fabian, E. S., Lent, R. W., \& Willis, S. P. (1998). Predicting work transition outcomes for students with disabilities: Implications for counselors. Journal of Counseling \& Development, 76, 311-316.

Foundation, M. (2008). Bridges from school to work: Participant database forms and files manual.

Foundation, M. (2012). Collaborators Bridges From School to Work Retrieved January 14, 2012, 2012, from http://www.bridgestowork.org/ioinbridges/collaborators/

Foundation, M. (2012). What We Do Retrieved 2-12-12, 2012, from http://www.bridgestowork.org/about-bridges/what-we-do/ 
Gardecki, R. M. (2001). Racial differences in youth employment. Monthly Labor Review, 51-67.

Gerry, M. H., \& Certo, N. J. (1992). Current activity at the federal level and the need for service integration. The Future of Children, Spring, 118-126.

Hackett, G., \& Bryars, N. M. (1996). Social cognitive career theory and career development of African American Women. The Career Development Quarterly, 44, 322-340.

Hasazi, S. B., Furney, K. S., \& DeStefano, L. (1999). Implementing the IDEA transition mandates. Exceptional Children, 65, 555-566.

Hasnain, R., \& Balcazar, F. (2009). Predicting community - versus facility - based employment for transition-aged young adults with disabilities: The role of race, ethnicity, and support systems. Journal of Vocational Rehabilitation, 31, 175-188.

Hitchings, W. E., Luzzo, D. A., Ristow, R., Horvath, M., Retish, P., \& Tanners, A. (2001). The career development needs of college students with learing disabilities: In their own words. Learning Disabilities Research \& Practice, 16, 8-17.

Hitchings, W. E., Retish, P., \& Horvath, M. (2005). Academic preparation of adolescents with disabilities for postsecondary education. Career Development for Exceptional Individuals, 28(1), 36-35.

PL 108-446, IDEA C.F.R. (2004).

Ihlanfeldt, K. R. (1992). Introduction Job accessibility and the employment and school enrollment of teenageers. Kalamazoo, MI: W.E. Upjohn Institute for Employment Research. 
Janiga, S. J., \& Costenbader, V. (2002). The transition from high school to postsecondary education for students with learning disabilities: A survey of college service coordinators. Journal of Learning Disabilities, 35(5), 463-470.

Karpur, A., Clark, H. B., Caproni, P., \& Sterner, H. (2005). Transition to adult roles for studens with emotional/behavioral disturbances: A follow-up study of student exiters from Steps-to-Success. Career Development for Exceptional Individuals, 28(1), 36-46.

Kenny, M. E., \& Bledsoe, M. (2005). Contributions of the relational context to career adaptability among urban adolescents. Journal of Vocational Behavior, 66, 257-272.

Kochhar-Bryant, C. A., \& Greene, G. (2009). Pathways to successful transition for youth with disabilities: A developmental process (Vol. 2). Upper Saddle River, NJ: Merrill/Pearson.

Labor, U. S. D. o. (2010). Wage and Hour Division (WHD) Retrieved 2-12-12, from http://www.dol.gov/whd/minwage/coverage.htm

Lindstrom, L. E., \& Benz, M. R. (2002). Phases of career development: Case studies of young women with learning disabilities. Exceptional Children, 69(1), 67-83.

Luecking, R. G., \& Certo, N. J. (2002, December 2002). Information Brief: Addressing Trends and Developments in Secondary Education and Transition Retrieved January 9, 2012, 2012, from

http://www.ncset.org/publications/viewdesc.asp?id=705

Luke, D. A. (2004). Multilevel Modeling. Thousand Oaks, CA: Sage Publications, Inc. 
Mason, C., Field, S., \& Sawilowsky, S. (2004). Implementation of self-determination activities and student participation in IEPs. Exceptional Children, 70(4), 441451.

Mayerson, A. (2006). The history of the ADA: A movement perspective Retrieved 212-12, from Disability Rights Education and Defense Fund Milgore, A., Mank, D., Grossi, T., \& Rogan, P. (2007). Integrated employment or sheltered workshops: Preferences of adults with intellectual disabilities, their families, and staff. Journal of Vocational Rehabilitation, 26(1), 5-19.

Newman, L. (2005). Family involvement in the educational development of youth with disabilities A Special Topic Report of Findings from the Natinoal Longitudinal Transition Study-2 (NTLS-2). Menlo Park, CA: SRI International.

Newman, L., Wagner, M., Knokey, A., Marder, C., Nagle, K., Shaver, D., et al. (2011). The post-high school outcomes of young adults with disabilities up to 8 years after high school A Report From the National Longitudinal Transition Study-2 (NTLS-2). Menlo Park, CA: SRI International.

Newman, L., Wagner, M., Knokey, A.-M., Marder, C., Nagle, K., Shaver, D., et al. (2011). The post-high school outcomes of young adults with disabilities up to 8 years after high school. In N. L. T. S.-. (NTLS-2) (Ed.), National Longitudinal Transition Study-2 (NTLS-2). Menlo Park, CA: SRI International.

O'Regan, K. M., \& Quigley, J. M. (1996). Teenage employment and the spatial isolation of minority and poverty households. 1996, XXXI(3), 692-702.

Pumpian, I., Fisher, D., Certo, N. J., \& Smalley, K. (1997). Changing jobs: An essential part of career development. Mental Retardation, 35(68-84). 
Raghnuathan, T. E., Lepkowski, J. M., Van Hoewyk, J., \& Solenberger, P. (2001). A multivariate technique for multiply imputing missing values using a sequence of regression models. Survey Methodology, 27(1), 85-95.

Raudenbush, S., Bryk, A., Cheong, Y. F., \& Congdon, R. (2001). HLM5: Heirarchical Linear and Nonlinear Modeling. Lincolnwood, IL: Scientific Software International.

Research, N. C. f. S. E. (n.d.). Study Design and Methodology - National Longitudinal Transition Study 2 Retrieved March 16, 2012, March 16, 2012, from http://www.nlts2.org/studymeth/index.html

Sax, C. L., Noyes, D., \& Fisher, D. (n.d.). High school inclusion + seamless transition = desired outcomes: A brief report Retrieved January 9, 2012, 2012, from http://www.ncset.hawaii.edu/institutes/mar2002/papers/pdf/HIGH\%20SC HOOL\%20INCLUSION.pdf

Sontag, J. C. (1996). Toward a comprehensive theoretical framework for disability research: Bronfenbrenner revisited. The Journal of Special Education, 30(3), 319-344.

Statistics, B. B. o. L. (2012). The employment situation - December 2011 Retrieved January 14, 2012, 2012, from http://www.bls.gov/news.release/pdf/empsit.pdf

Statistics, B. o. L. (2011). The Employment Situation - October 2011. Washington, DC: Bureau of Labor Statistics.

Syzmanski, E. M., Hanley-Maxwell, C., \& Asselin, S. B. (1992). Systems interface: Vocational rehabilitation, special education, and vocational education. In F. R. 
Rusch, L. DeStefano, J. Chadsey-Rusch, L. A. Phelps \& E. Syzmanski (Eds.), Transition from school to adult life. Models, linkages, and policy. Sycamore, IL: Sycamore.

Transition, N. A. f. S. E. a. (2010). NASET Overview Retrieved 2-12-12, 2012, from http://www.nasetalliance.org/about/index.htm

Transition, N. A. f. S. E. a. (n.d.). National standards and quality indicators: Transition toolkit for systems improvement Retrieved 2-12-12, 2012, from http://www.nasetalliance.org/docs/TransitionToolkit.pdf

Waddoups, J., \& Assane, D. (1997). Duration and mobility of young male workers in a segmented labor market. Applied Economics Letters, 4, 173-176.

Wagner, M., \& Blackorby, J. (1996). Transition from high school to work or college: How special education students fare. The Future of Children, 6(1), 103-120.

Wagner, M., Newman, L., Cameto, R., Garza, N., \& Levine, P. (2005). After high school: A first look at the postschool experiences of youth with disabilities. In N. L. T. S. 2 (Ed.). Menlo Park, CA: Office of Special Education Programs, U.S. Department of Education.

Wehmeyer, M. L. (1999). A fucntional model of self-determination: Describing development and implementing instruction. Focus on Autism and Other Developmental Disabilities, 14(1), 53-62.

Wehmeyer, M. L., Agran, M., \& Hughes, C. (1998). Teaching self-determination skills to students with disabilties: Basic skills for successful transition. Baltimore: Paul H. Brookes. 
Wehmeyer, M. L., \& Lawrence, M. (1995). Whose future is it anyway? Promoting student involvement in transition planning. Career Development for Exceptional Individuals, 18(2).

Wehmeyer, M. L., \& Palmer, S. B. (2003). Outcomes for students with cognitive disabilities three-years after high school: The impact of self-determination. Education and Training in Developmental Disabilities, 38(2), 131-144.

Wehmeyer, M. L., \& Schwartz, M. (1998). The relationship between selfdetermination and quality of life for adults with mental retardation. Education and Training in Developmental Disabilities, 33(1), 3-12.

Wittenburg, D. C., \& Loprest, P. J. (2007). Early transition experiences of transitionage child SSI recipients: New evidence from the National Survey of Children and Families. Journal of Disability Policy Studies, 18(3), 176-187. 